\title{
Effects of larval diapause and the juvenile hormone analog, fenoxycarb, on testis development and spermatogenesis in the wax moth, Galleria mellonella (Lepidoptera: Pyralidae)
}

\author{
Piotr Bebas ${ }^{1}$, Bronislaw CYMBOROWSKI ${ }^{1}$, Michalina KAZEK ${ }^{2}$ and Marta Anna POLANSKA ${ }^{1, *}$ \\ ${ }^{1}$ Department of Animal Physiology, Faculty of Biology, University of Warsaw, 1 Miecznikowa Str., 02-096 Warsaw, Poland; \\ e-mails: piotrbe@biol.uw.edu.pl, bron@biol.uw.edu.pl, martap@biol.uw.edu.pl \\ ${ }^{2}$ Institute of Parasitology, Polish Academy of Sciences, 51/55 Twarda Str., 00-818 Warsaw, Poland; \\ e-mail:m.kazek@twarda.pan.pl
} Key words. Lepidoptera, Pyralidae, Galleria mellonella, wax moth, juvenile hormone analogs, larval diapause, larval testes, vas
deferens, spermatogenesis

\begin{abstract}
Facultative diapause in the wax moth, Galleria mellonella, occurs in the final larval instar. Application of juvenile hormone analogs (JHAs) to the larvae of this species has similar effects to diapause, in terms of prolonged development of the larval stages and the arrest in the metamorphosis of internal organs. Here, we focus on testes development and spermatogenesis at the end of larval development in G. mellonella, how they are affected by diapause induced by an environmental decrease in temperature to $18^{\circ} \mathrm{C}$ and the application of a JHA (fenoxycarb) to larvae. Because neither testis development nor spermatogenesis are described in detail for this species, we examined them in individuals not in diapause during the period from the last larval instar to the newly emerged adult and present a timetable of changes that occur in the development of testes in this species. These observations have increased the very limited data on the course of spermatogenesis in pyralid insects. We then used these data for comparative analysis of testes in larvae from two experimental groups: individuals in diapause and those treated with fenoxycarb. The results on the general morphology testes revealed obvious degenerative changes caused by fenoxycarb (but not by diapause), including testicular wall hypertrophy and disarrangement of testicular follicles. Moreover, treatment with fenoxycarb finally resulted in the disintegration of nearly all testicular cyst-containing germ cells at different stages of spermatogenesis, a situation never previously described in the literature. In contrast, the main effect of diapause on testes was merely the degeneration of spermatocytes in the proximal regions of the testicular follicles. Finally, the TUNEL analyses, revealed that the degenerative changes in germ cells were apoptotic in character in the testes of both individuals in diapause and fenoxycarb-treated males.
\end{abstract}

\section{INTRODUCTION}

In Lepidoptera, the most intensive testicular growth, caused by an increase in the frequency of mitotic divisions of the primary germ cells, occurs during the last larval instar (Friedländer et al., 2005). At this stage, each pair of testes is composed of four follicles with three distinct areas filled with gonial cells at different stages of development (Fig. 1) (Klowden, 2004, 2013). In most Lepidoptera, at the end of their larval development (pre-pupal stage), the paired kidney-shaped testes fuse into a single organ that then undergoes torsion such that pupae and adult males possess a single gonad consisting of eight twisted chambers, known as testicular follicles (TF), (Cholodkovsky, 1880; Drecktrah, 1966; Jones, 1973; LaChance \& Olstad, 1988; Pereira \& Santos, 2015). It has been clearly shown, at least in some species, that simultaneously with the testis fusion-torsion process, spermiogenesis of developmentally advanced spermatids is initiated, leading to the appearance of mature spermatozoa bundles that increase in number with the progression of metamorphosis (Chaudhury \& Raun, 1966; Nowock, 1972, 1973; Jones et al., 1984; Corsato-Alvarenga et al., 1987). The population of primary germ cells usually decreases as the germarium in each $\mathrm{TF}$ degenerates or at least decreases and is less active (Sonoli \& Hooli, 1992; Witalis \& Godula, 1993).

In insects, the germ cells derived from single primary spermatogonia remain interconnected after division and are enveloped in somatic cells (known as cyst cells), thus forming a structure consisting of cysts that ultimately form elongated bundles of spermatozoa (Phillips, 1970; Dumser, 1980; Dallai, 2014). In Lepidoptera, spermatogenesis is dichotomous because the spermatocytes undergo differ-

\footnotetext{
* Corresponding author; e-mail: martap@biol.uw.edu.pl
} 
A

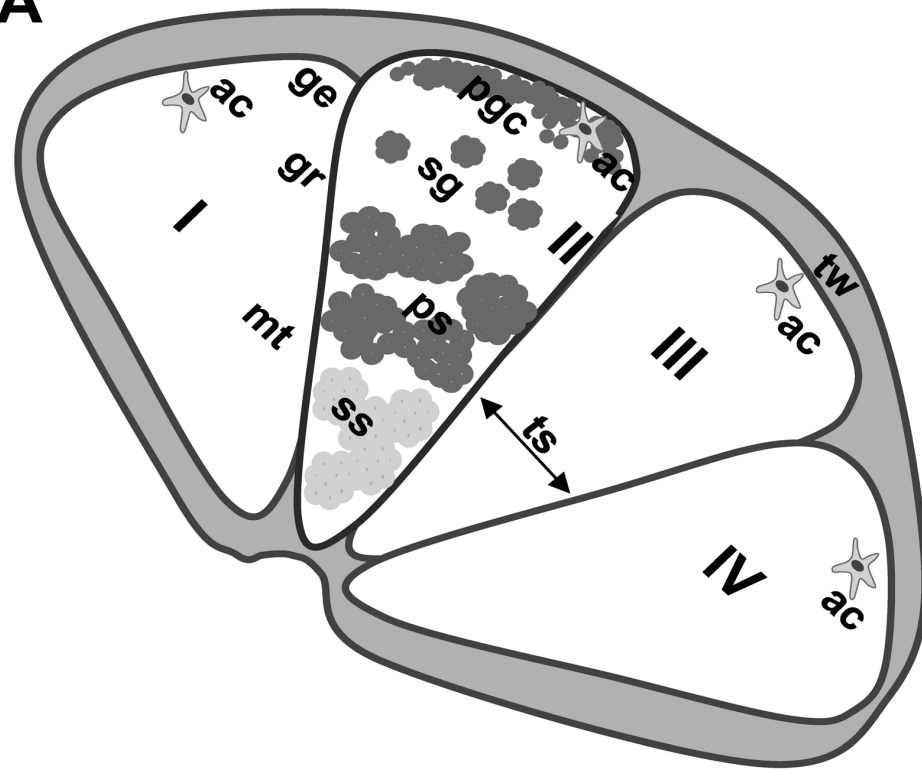

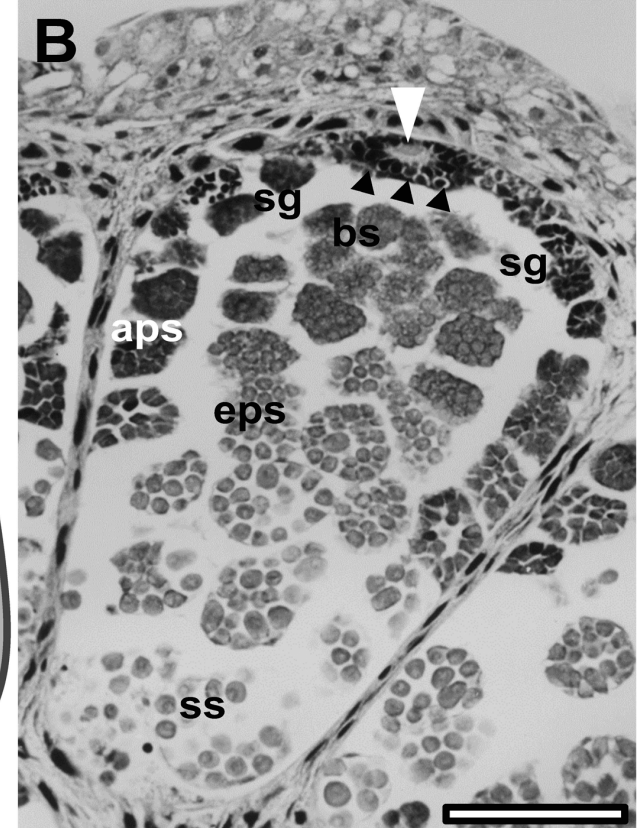
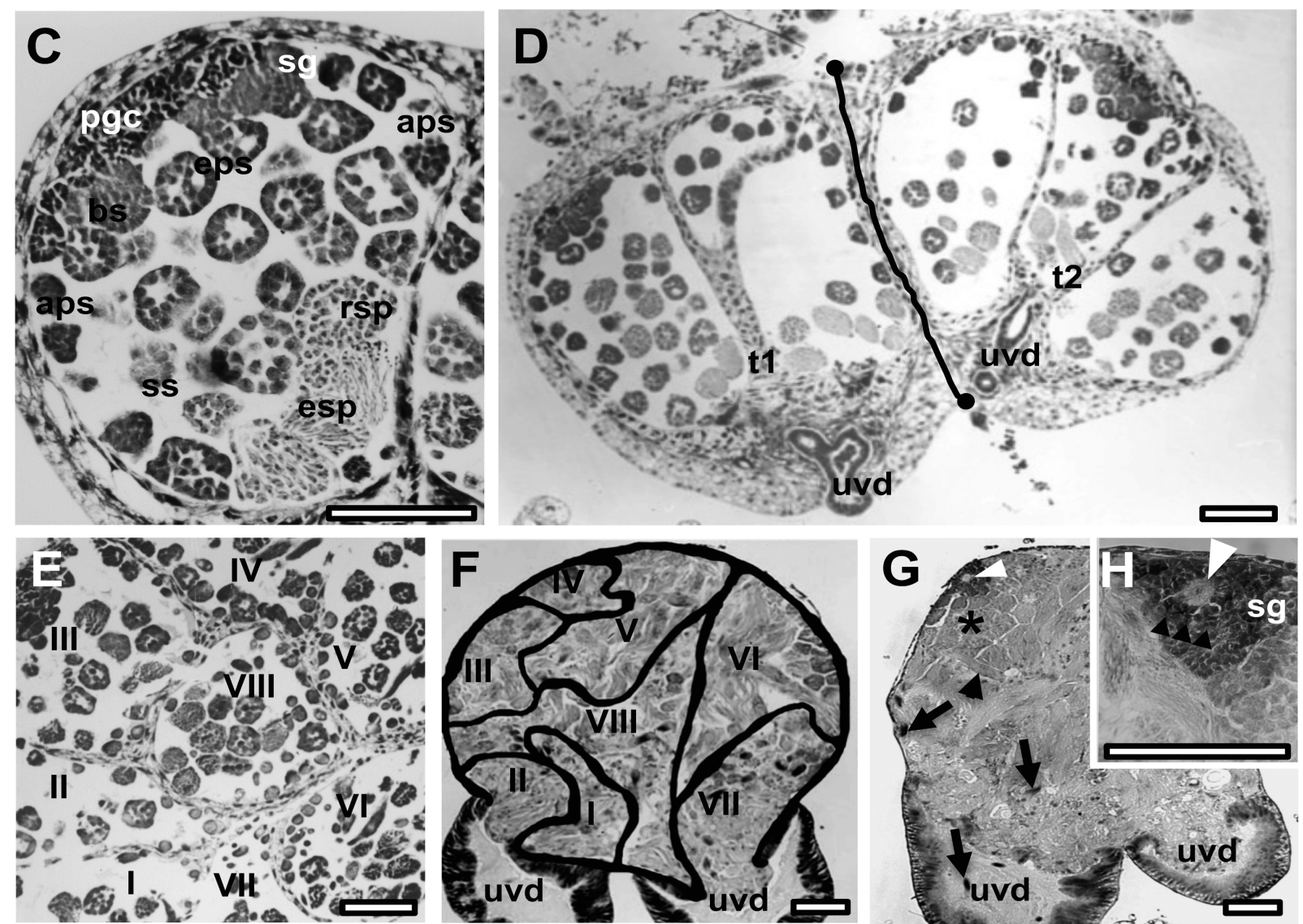

Fig. 1. General morphology of male gonads during larval-adult development in G. mellonella. A - schematic representation of a testis in the last $(\mathrm{VII}$ ) larval instar; B and C - light microscopy photographs of a longitudinal section of the TF in one and seven-day-old larvae of the last instar, respectively; D - microphotograph of a longitudinal section of two testes (t1 and t2 - the black line marks the border between the testes) during the fusion process at the pre-pupal stage, with recognizable paired UVD present at the base of the testes; $\mathrm{E}$ - microphotograph of a cross-section of pupal testis; F-G - longitudinal sections of testes from 1 and 3-day-old adults, respectively marked ts (black lines) in $\mathrm{F}$ and different populations of cells indicated in $\mathrm{G}$ (differentiating germ cells - asterisk; apyrene sperm bundle in testes - black arrowhead, eupyrene sperm bundles in testes and UVD - black arrows); and $\mathrm{H}$ - higher magnification of the germarium in adult testes. Roman numerals (I-VIII) denote the testicular follicles (TF); ts - testicular septa separating TF; ac - Verson's (apical) cell, also indicated on microphotographs by the white arrowhead; ge - germarium; gr, growth zone of TF; mt - maturation zone of TF; pgc - primary gonial cells, also indicated by a series of black arrowheads; $\mathrm{sg}$ - spermatogonial cysts; ps, cysts with primary spermatocytes (including: bs - bipotential spermatocytes, aps - apyrene primary spermatocytes and eps - eupyrene primary spermatocytes); ss - cysts with secondary spermatocytes; rsp - cysts with round spermatids, esp. cysts with elongated spermatids; and uvd, upper vasa deferentia. Scale bars $=50 \mu \mathrm{m}$. 
entiation into two types, leading to the formation of nucleated (eupyrene) and un-nucleated (apyrene) spermatozoa (Mancini \& Dolder, 2004; Friedländer et al., 2005; Dallai, 2014; Dallai et al., 2016). During release from the testis into the upper vasa deferentia (UVD), both types of spermatozoa are liberated from cyst cells that remain in the testis and then undergo programmed cell death followed by fragmentation (Giebultowicz et al., 1997; Gvakharia et al., 2003). In the UVD, apyrene spermatozoa in each bundle are associated for a short time after release and then disperse, whereas eupyrene spermatozoa remain in tight bundles during transfer in the reproductive ducts of males (Riemann \& Giebultowicz, 1992; Friedländer et al., 2001).

The processes occurring in the male reproductive system of insects are hormonally regulated, mainly by ecdysteroids and juvenile hormones (JHs) (Raikhel et al., 2005). Ecdysteroids affect the development of testes and accessory structures, e.g., seminal ducts, and positively regulate spermatogenesis by increasing both the number of germ cell divisions and their subsequent differentiation into more advanced stages; for a review, see (Happ, 1992; Friedländer, 1997; Belles \& Maestro, 2005) and publications cited therein. The effect of JHs on testis development and spermatogenesis is discussed but poorly understood and varies significantly even in closely related species (Hartfelder, 2000). The majority of the data on this subject was published in the 1960s and 1970s; for a review, see also (Wyatt \& Davey, 1996; Slama, 2015) and publications cited therein. Moreover, nearly all of these studies are based on the exogenous application of JHs or their analogs (JHAs, including insect growth regulators - IGRs) to insects. Interesting observations also come from studies on the effects of diapause on testes development in terms of its regulation by hormones, including ecdysteroids and JHs, the levels of which change depending on the stage and timing of dormancy (Friedländer et al., 2005). In males, it coincides with the maturity of the testes and a high rate of germ cell differentiation. It is also known that diapause in these insects results in a slow down in spermatogenesis, which is not completely arrested but features incomplete differentiation and dying germ cells at different stages of development (Mochida \& Yoshimeki, 1962; Chippendale \& Alexander, 1973; Friedländer \& Benz, 1982; Friedländer \& Reynolds, 1992; Friedländer, 1997; Kubo-Irie et al., 1999; Friedländer et al., 2005). In larvae in diapause, most of the not fully differentiated germ cells undergo lysis and are successively replenished from a pool of dividing stem cells present in the germarium of each TF (Friedländer \& Benz, 1982; Friedländer, 1997). Moreover, the developmental stage at which germ cells lyse seems to vary between species (Friedländer et al., 2005).

The aim of the present study was to compare the ontogeny of the male gonads of the wax moth Galleria mellonella during larval diapause and after treatment with fenoxycarb, a carbamate IGR with potent insect juvenile hormone activity. First, we examined the morphology of testes of individuals not in diapause during the period from the last larval instar to the newly emerged adult, and the results were used as background for a comparative analysis of testes in insects subjected to two experimental treatments: induction of diapause and application of fenoxycarb. Light microscopy and transmission electron microscopy (TEM) were used to record characteristic degenerative changes in the germ cells of larvae from the experimental groups and some the abnormalities in spermatogenesis in the fenoxycarb-treated individuals (compared with individuals not in diapause and in diapause). The TUNEL method was used to label apoptotic cells and confirm the apoptotic characteristics of the degenerative changes.

\section{MATERIALS AND METHODS}

\section{Insect breeding and treatment}

The wax moth, Galleria mellonella, was reared in constant darkness at a temperature of $30 \pm 1^{\circ} \mathrm{C}$ and relative humidity of approximately $60 \%$. Larvae were fed on a semi-synthetic diet (Sehnal, 1966). For the experiments, 1-day-old larvae of the final $\left(\mathrm{VII}^{\text {th }}\right)$ instar were selected and placed in groups of 10 in plastic dishes and maintained at $30 \pm 1{ }^{\circ} \mathrm{C}$ (individuals in the control

Fig. 2 (right). Light microscopy photographs of germ cells in the testes and the upper vasa deferentia of G. mellonella. A - primary gonial cells (pgc) with a somatic Verson's cell (arrowhead) constituting the spermatogonial cysts; B-D - cysts with spermatogonia in different stages of development ( $n$, dark stained nuclei); $E$ - early (bipotential) spermatocytes (most likely at the pachytene stage) with partially condensed chromatin resulting in heterogeneously stained nuclei (n); F and G - apyrene and eupyrene spermatocytes, respectively, with pyknotic bodies located centrally in the nuclei (arrows); $\mathrm{H}$ - secondary spermatocytes after meiosis I (some cells before cytokinesis, containing two nuclei - arrow); I - secondary spermatocytes before and during meiosis II (chromosomes oriented on the metaphase plate are indicated by arrowheads), differentiated into spermatids; J - round spermatids condensed, with dark nuclei (arrows); K - elongated spermatids with dense spherical nuclei (pointed to by arrows); L - late spermatids or early apyrene spermatozoa organized in bundles with attached nuclear material (white arrow) and long flagellae (f); M - early eupyrene spermatozoa packed in bundles with dark-stained nuclei (arrows); N-O - fully developed bundles of apyrene and eupyrene spermatozoa, respectively - tightly packed apyrene cysts are located at the periphery of testes (edge of one bundle indicated by a series of arrows), while eupyrene are more loosely distributed in the centers of testes and recognizable by stained bundles of nuclei (arrows); P-S - series of longitudinal sections through the UVD (e epithelium of the UVD wall; asterisk - lumen of the UVD) when the release of sperm is initiated ( $P$ - the UVD lumen without any stained material; $Q$ - accumulation of slightly stained secretory material in the UVD lumen (series of arrows) precedes sperm release from testes; $\mathrm{R}$ - accumulation of apyrene sperm (arrowheads in R) in the UVD, which are liberated from bundles to form a hair-like mass; and S eupyrene sperm packed in bundles with strongly stained nuclei (arrows) join apyrene cells (arrows heads)). Scale bars $=10 \mu \mathrm{m}$. In the table located below the microphotographs is a compilation of data from comparative studies of spermatogenesis and events associated with the initiation of the release of sperm during the ontogeny of insects not in diapause, in diapause and treated with fenoxycarb. Letters in the first column of the table correspond to letters used to designate microphotographs with cells in testes or events associated with the release of sperm into the UVD. VII - last $\left(7^{\text {th }}\right)$ larval instar, PP - prepupae, P - pupae, A - adults (moths), D - larvae in diapause, F - larvae treated with fenoxycarb; Arabic numerals denote the day of the given stage, the time remaining in diapause or the number of days after administration of fenoxycarb that the gonads were investigated; signs used in the table are as follows: $0=$ when not present, $+=$ when present, - when not applicable. 

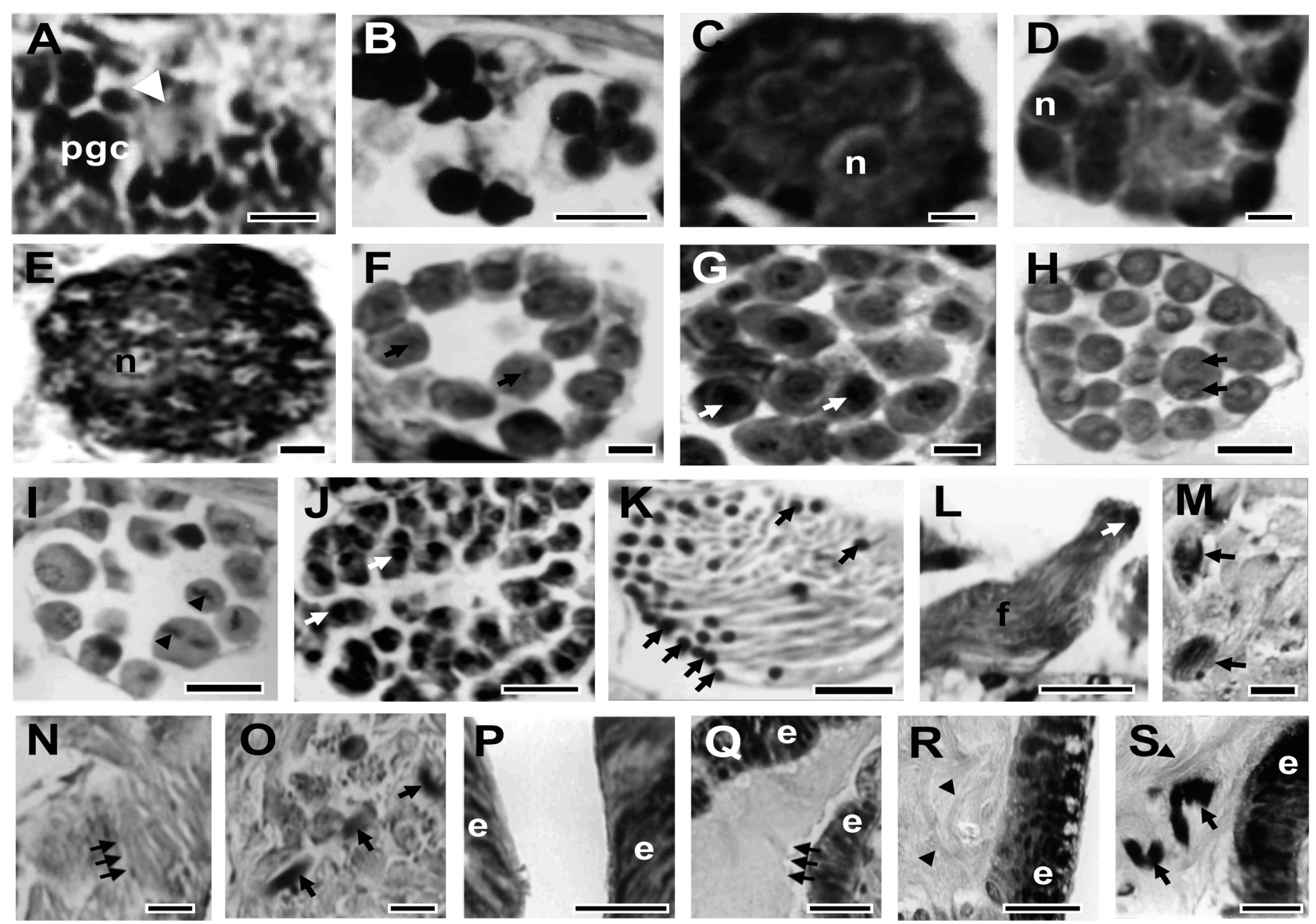

\begin{tabular}{|c|c|c|c|c|c|c|c|c|c|c|c|c|c|c|}
\hline \multicolumn{2}{|c|}{ Cell types (stages) } & $\begin{array}{l}\text { VII } \\
1\end{array}$ & $\begin{array}{l}\text { VII } \\
7\end{array}$ & $\begin{array}{l}\mathrm{PP} \\
1\end{array}$ & $\begin{array}{l}\mathbf{P} \\
3\end{array}$ & $\begin{array}{l}P \\
5\end{array}$ & $\begin{array}{l}A \\
1\end{array}$ & $\begin{array}{c}\text { D } \\
30\end{array}$ & $\begin{array}{l}D \\
60\end{array}$ & $\begin{array}{l}\text { D } \\
90\end{array}$ & $\begin{array}{l}\mathrm{F} \\
7\end{array}$ & $\begin{array}{l}F \\
14\end{array}$ & $\begin{array}{r}F \\
21\end{array}$ & $\begin{array}{l}F \\
28\end{array}$ \\
\hline $\mathbf{A}$ & Verson's (apical) cell & + & + & + & + & + & + & + & + & + & 0 & 0 & 0 & $\mathbf{0}$ \\
\hline B & Primary gonial cells & + & + & + & + & + & + & + & + & + & + & + & 0 & $\mathbf{0}$ \\
\hline C & Spermatogonia & + & + & + & + & + & + & + & + & + & + & + & $\mathbf{0}$ & $\mathbf{0}$ \\
\hline D & Late spermatogonia & + & + & + & + & + & + & + & + & + & + & + & 0 & $\mathbf{0}$ \\
\hline$E$ & Primary bipotential spermatocytes & + & + & + & + & + & + & + & + & + & + & + & 0 & $\mathbf{0}$ \\
\hline $\mathbf{F}$ & Primary apyrene spermatocytes & + & + & + & + & + & + & + & + & + & + & $\mathbf{0}$ & $\mathbf{0}$ & $\mathbf{0}$ \\
\hline G & Primary eupyrene spermatocytes & + & + & + & + & + & + & + & + & + & + & + & $\mathbf{0}$ & $\mathbf{0}$ \\
\hline $\mathbf{H}$ & Early secondary spermatocytes & 0 & + & + & + & + & + & 0 & 0 & 0 & 0 & 0 & 0 & $\mathbf{0}$ \\
\hline $\mathbf{I}$ & Late secondary spermatocytes & 0 & + & + & + & + & + & 0 & $\mathbf{0}$ & $\mathbf{0}$ & $\mathbf{0}$ & $\mathbf{0}$ & $\mathbf{0}$ & $\mathbf{0}$ \\
\hline $\mathbf{J}$ & Round spermatids & 0 & + & + & + & + & + & 0 & $\mathbf{0}$ & $\mathbf{0}$ & $\mathbf{0}$ & $\mathbf{0}$ & $\mathbf{0}$ & $\mathbf{0}$ \\
\hline $\mathbf{K}$ & Elongating spermatids & $\mathbf{0}$ & + & + & + & + & + & 0 & $\mathbf{0}$ & $\mathbf{0}$ & $\mathbf{0}$ & $\mathbf{0}$ & $\mathbf{0}$ & $\mathbf{0}$ \\
\hline $\mathbf{L}$ & $\begin{array}{l}\text { Late spermatids/early apyrene sperm } \\
\text { bundles }\end{array}$ & 0 & 0 & $\mathbf{0}$ & + & + & + & 0 & 0 & 0 & $\mathbf{0}$ & 0 & $\mathbf{0}$ & $\mathbf{0}$ \\
\hline $\mathbf{M}$ & Early eupyrene sperm bundles & 0 & $\mathbf{0}$ & $\mathbf{0}$ & $\mathbf{0}$ & + & + & 0 & $\mathbf{0}$ & $\mathbf{0}$ & $\mathbf{0}$ & $\mathbf{0}$ & $\mathbf{0}$ & $\mathbf{0}$ \\
\hline $\mathbf{N}$ & $\begin{array}{l}\text { Tightly packed apyrene sperm } \\
\text { bundles }\end{array}$ & 0 & 0 & $\mathbf{0}$ & 0 & + & + & 0 & $\mathbf{0}$ & $\mathbf{0}$ & $\mathbf{0}$ & $\mathbf{0}$ & $\mathbf{0}$ & $\mathbf{0}$ \\
\hline 0 & $\begin{array}{l}\text { Tightly packed eupyrene sperm } \\
\text { bundles }\end{array}$ & 0 & 0 & $\mathbf{0}$ & $\mathbf{0}$ & $\mathbf{0}$ & + & 0 & $\mathbf{0}$ & 0 & 0 & 0 & 0 & 0 \\
\hline
\end{tabular}

\begin{tabular}{|c|c|c|c|c|c|c|c|c|c|c|c|c|c|c|}
\hline \multicolumn{15}{|c|}{ Events in the upper vas deferens (UVD) } \\
\hline $\mathbf{P}$ & UVD without secretion in the lumen & - & - & - & + & $\mathbf{0}$ & $\mathbf{0}$ & - & - & - & - & - & - & - \\
\hline $\mathbf{Q}$ & UVD with secretion in the lumen & - & - & - & + & + & + & - & - & - & - & - & - & - \\
\hline $\mathbf{R}$ & $\begin{array}{l}\text { Apyrene spermatozoa present in the } \\
\text { UVD lumen }\end{array}$ & - & - & - & $\mathbf{0}$ & + & + & - & - & - & - & - & - & - \\
\hline S & $\begin{array}{l}\text { Apyrene and eupyrene spermatozoa } \\
\text { present in the UVD lumen }\end{array}$ & - & - & - & 0 & 0 & + & - & - & - & - & - & - & - \\
\hline
\end{tabular}


group and the group treated with fenoxycarb) or transferred to $18 \pm 1^{\circ} \mathrm{C}$ for 30,60 or 90 days to induce and maintain diapause (Smietanko et al., 1989; Mikolajczyk \& Cymborowski, 1993; Cymborowski, 2000). One $\mu 1$ of a solution of fenoxycarb in acetone with a final concentration of $1 \mu \mathrm{g} / \mu \mathrm{l}$ was applied to the dorsum of larvae. Fenoxycarb-treated insects were maintained for 28 days, in which time the larval-pupal intermediates or degenerate pupae usually developed. As controls, we used untreated insects or those dorsally treated with $1 \mu$ lof acetone.

\section{Preparation and light microscope studies of testes}

Testes were dissected from final stage instar larvae (1, 3, 5 or 7 day old), prepupae, pupae (in the middle of metamorphosis) and newly emerged adults ( 1 day old) reared under optimal conditions. To characterize the effects of diapause and fenoxycarb on the development of testes, last instar larvae after 30,60 , or 90 days (kept at $18^{\circ} \mathrm{C}$ ) and $7,14,21$ or 28 days, respectively, were used. As controls for insects treated with fenoxycarb, untreated 7 day old last instar larvae treated with acetone were used (the course of larval development in both control groups did not differ from normal; thus, day 7 was the final day before the onset of metamorphosis). The testes were dissected and immediately fixed for $4 \mathrm{~h}$ at room temperature in a solution of $4 \%$ paraformaldehyde in $0.1 \mathrm{M}$ Na-phosphate buffered saline (PBS), $\mathrm{pH} 7.2$. After fixation, the testes were washed three times in PBS and then their general morphology examined using confocal or classical light microscopy. For the latter, testes were dehydrated in an increasing ethanol series and xylene, embedded in paraffin wax (melting temperature $56^{\circ} \mathrm{C}$; POCH S.A., Gliwice, Poland), cut into 6 - $\mu \mathrm{m}$-thick sections and mounted on gelatin-coated glass slides. Following paraffin removal and rehydration, the sections were stained with iron hematoxylin according to Heidenhain as described previously (Polanska et al., 2005). Analysis of the sections and microphotography were done using an Axio Scope. A1 microscope (Carl Zeiss Microscopy GmbH, Jena, Germany) equipped with a ProgResMF ${ }^{\text {cool }}$ camera (Jenoptic, Jena, Germany). For the confocal microscopy studies, whole testes of larvae were blocked for $1 \mathrm{~h}$ with $1 \%$ bovine serum albumin (BSA; Jackson ImmunoResearch Laboratories, Inc., West Grove, PA, USA) in $0.1 \mathrm{M}$ PBS, $\mathrm{pH} 7.2$, containing $0.3 \%$ Triton X-100 (PBST). The blocking solution was then replaced with PBST containing $0.1 \%$ BSA and the F-actin-labelled fluorescent probe Texas Red-X Phalloidin (Molecular Probes, Eugene, OR, USA) at a final concentration of $40 \mathrm{nM}$. Following overnight incubation at $4^{\circ} \mathrm{C}$, the tissues were washed three times in $0.03 \%$ PBST and twice in PBS and were then mounted in Vectashield (Vector Laboratories, Inc., Burlingame, CA, USA) containing the nuclear marker DAPI. Preparations were viewed and photographed using a Zeiss LSM 780 NLO Confocal Microscope (Carl Zeiss Microscopy GmbH).

For the identification of apoptotic cells in paraffin sections of the testes, the terminal deoxynucleotidyl transferase (TdT) 2'-deoxyuridine-5' -triphosphate (dUTP) nick end labelling (TUNEL) method was used (for details, see Polanska et al., 2005). For this technique, digoxigenin (DIG)-labelled 11-dUTPs (Roche AG, Basel, Switzerland) were added to the 3'-OH end of DNA strand breaks using TdT (New England Biolabs, Ipswich, MA, USA) and visualized immunohistochemically using anti-DIG POD (horseradish-peroxidase, HRP)-labelled antibody (Roche AG), followed by antibody site binding localization using 3,3'-diaminobenzidine tetrahydrochloride (DAB) (Electron Microscopy Science, Hatfield, PA, USA) as a substrate for HRP. As a control for the TUNEL reaction, TdT was omitted from the reaction buffer.

\section{Transmission electron microscopy (TEM) studies of testes}

For TEM, standard tissue preparation procedures were followed (Hunter et al., 1993). In brief, the testes were fixed in $2.5 \%$ glutaraldehyde in $0.1 \mathrm{M}$ cacodylate buffer $(\mathrm{CB}), \mathrm{pH} 7.2$, for $2 \mathrm{~h}$ at $4^{\circ} \mathrm{C}$, followed by three washes in ice-cold CB. Post-fixation was carried out overnight by incubating the tissues in $1 \% \mathrm{OsO} 4$ at $4^{\circ} \mathrm{C}$ prepared on $\mathrm{CB}$. After three washes in $\mathrm{CB}$, the fixed tissues were dehydrated in an increasing ethanol gradient and propylene oxide (PO) and then saturated with Glycid ether 100 resin (EPON 812; SERVA Electrophoresis GmbH, Heidelberg, Germany) by incubating in the following mixtures of resin: $\mathrm{PO}-1: 3,1: 1,3: 1$ $(\mathrm{v} / \mathrm{v})$ and two changes of pure resin. Polymerization was done at $60^{\circ} \mathrm{C}$ for $48 \mathrm{~h}$. Ultrathin sections were cut using a Leica ULTRACUT R ultramicrotome (Leica Microsystems GmbH, Wetzlar, Germany) and stained using lead citrate and uranyl acetate (Hunter, 1993). The material was analyzed and photographed using a TESLA BS-500 TEM (Tesla Brno, Brno, Czech Republic).

\section{RESULTS}

\section{Overview of the changes in the testes and vasa deferentia of G. mellonella during development from larva to adult}

Cross-sections of testes from 1-day-old larvae of the last (VII ${ }^{\text {th }}$ instar revealed that each of the four testicular follicles (TF) was filled with easily distinguishable populations of germ cells in different stages of development (Fig. 1). The most distally (apically) located group of cells, which were strongly stained with Heidenhain's hematoxylin, were multipotent cells (primary gonial cells) that maintained physical contact with a single somatic Verson's (apical) cell, which together formed the germarium (Figs 1A, B and 2A, D). These maternal cells for predefinitive and definitive spermatogonia leave the germarium and subsequently form spermatogonial cysts located laterally in the upper part of the follicles. The upper-median zone of the follicles is occupied by bipotential spermatocytes that arise from spermatogonia (Figs $1 \mathrm{~B}$ and $2 \mathrm{E}$ ). These cells are closely packed in the cysts and ultimately differentiate into primary apyrene spermatocytes (usually more intensely stained) and primary eupyrene spermatocytes, which are visible in sections of testes at different stages of maturation (Figs $1 \mathrm{~B}$ and $2 \mathrm{~F}, \mathrm{G}$ ). At this stage, single cysts filled with secondary spermatocytes are also present in the testes of some individuals (Fig. 1B). Six days later (in 7-day-old larvae), the testes are rounder, and the aforementioned population of cells in each follicle has increased and includes germ cells at more advanced stages, including numerous secondary spermatocytes, round spermatids and spermatids at different stages of elongation (Figs $1 \mathrm{C}$ and $2 \mathrm{H}-\mathrm{K}$ ). In the pre-pupal stage, the testes are located very close to each other, indicating the beginning of the fusion process that results in the formation of a single gonad in early stage pupae (Fig. 1D). After fusion, the compartmentalization of the single gonad into follicles is maintained, and the single testis that is formed during this stage remains divided into 8 chambers (primarily belonging to paired larval testes) (Fig. 1E). Moreover, the fusion process is followed by torsion, which occurs during the first half of pupal development and results in the very irregular shape of the follicles 
D30

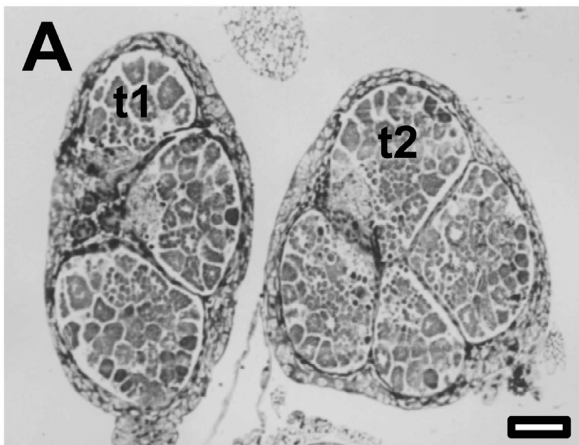

D60
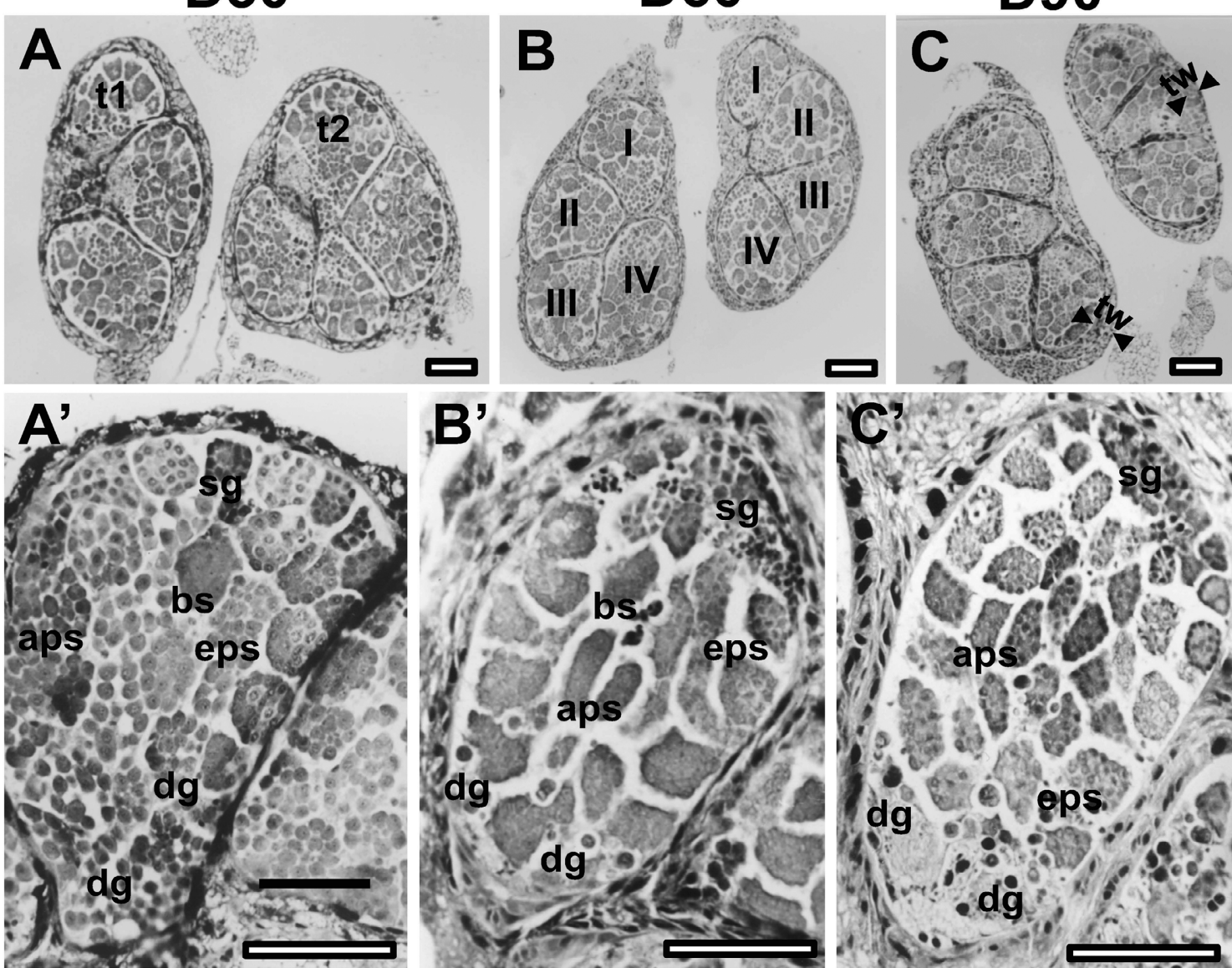

F7
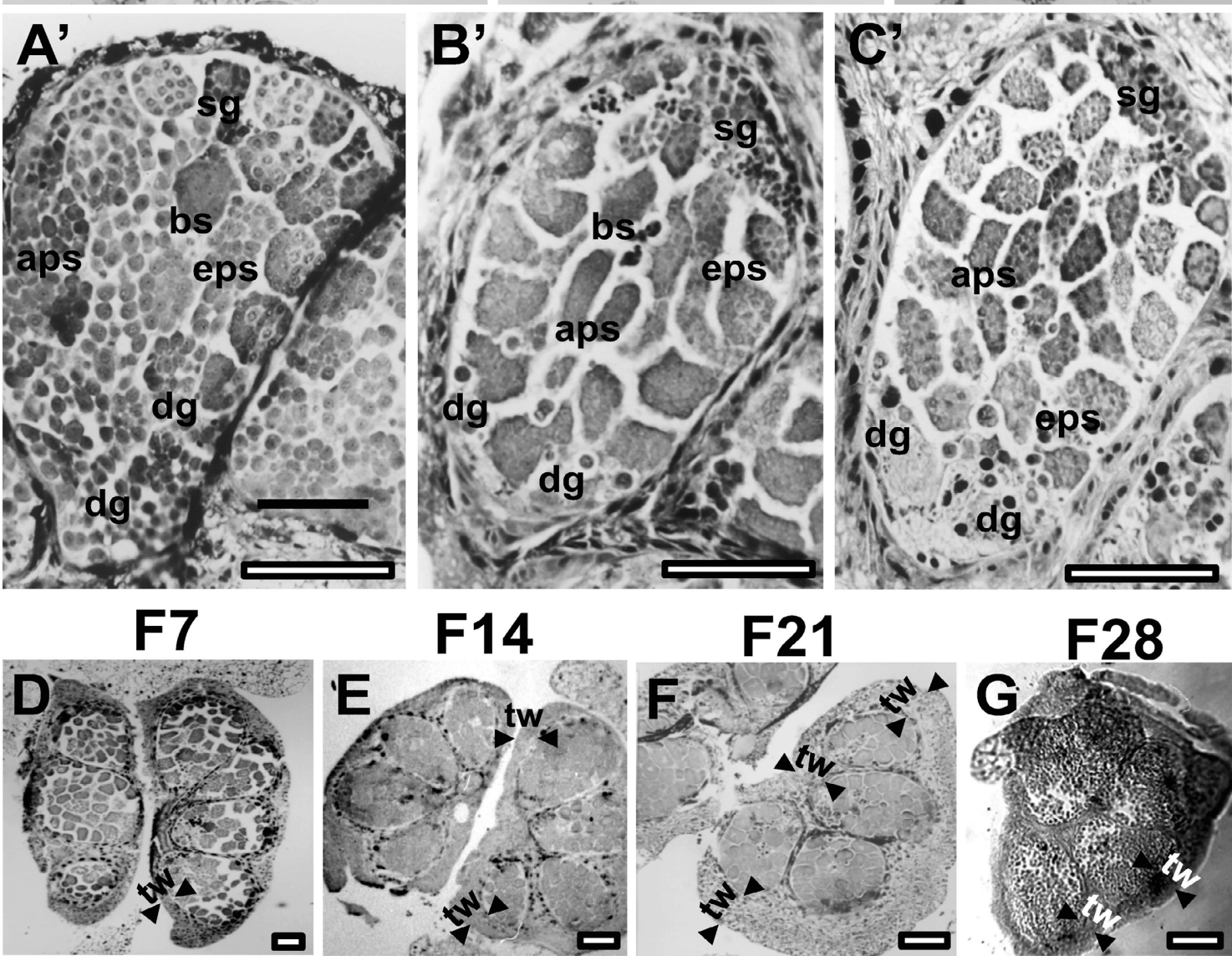

F21
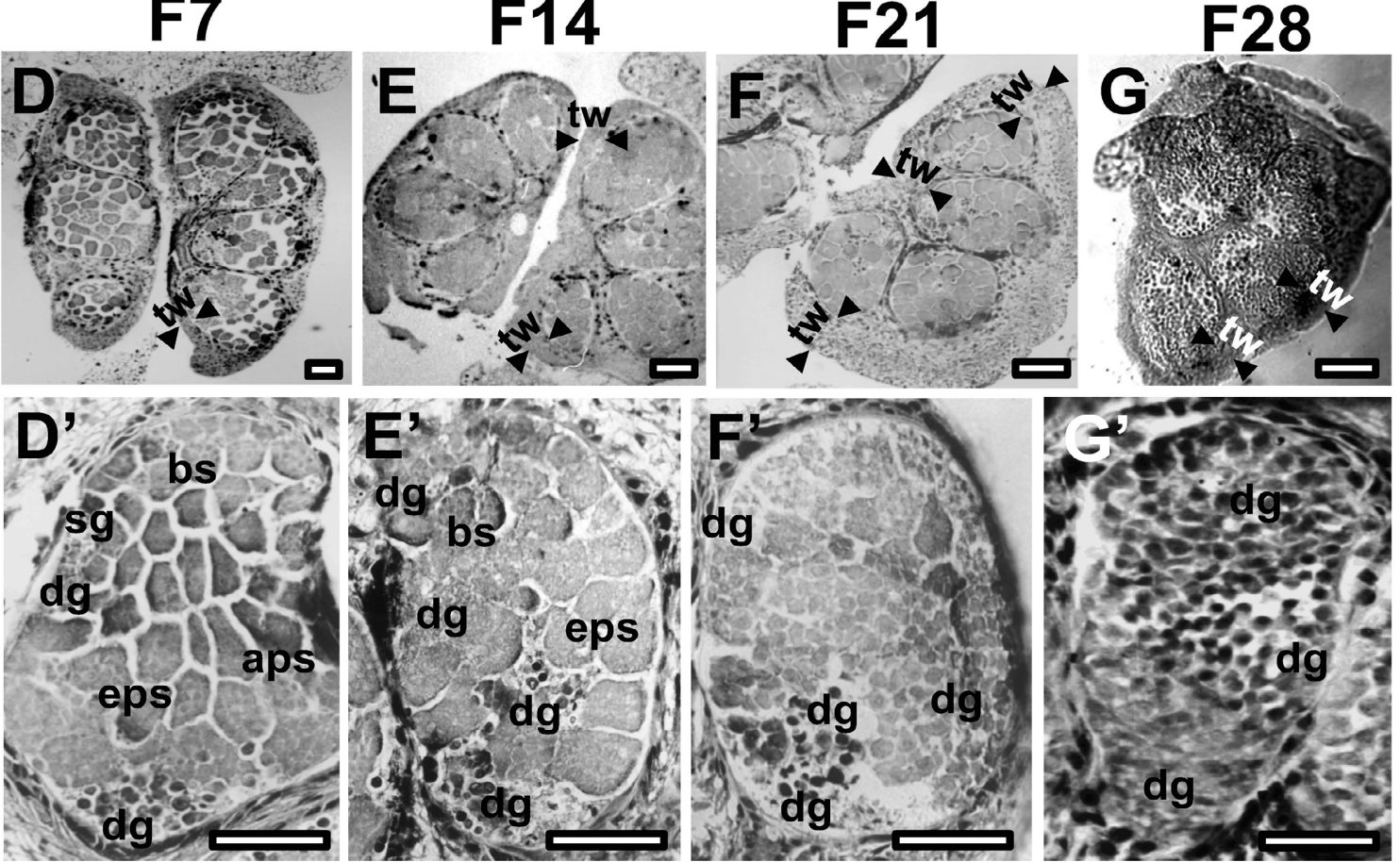

Fig. 3. Light microscopy photographs showing the general morphology of testes last-instar larvae of $G$. mellonella in diapause and treated with fenoxycarb. A, B and C are longitudinal sections of pairs of testes from individuals that have been in diapause for 30 (D30), 60 (D60) and 90 (D90) days, respectively, and higher magnifications of single testicular follicles, corresponding to A-C, are shown in $A^{\prime}-C^{\prime} ; D^{\prime}, E$, $F$ and G, with longitudinal section of pairs of testes from individuals on day 7 (F7), 14 (F14), 21 (F21) and 28 (F28) after the application of fenoxycarb; D'-G', single testicular follicles photographed at a higher magnification that corresponds to D-G. t1 and t2 - testes; I-IV - testicular follicles; tw - testicular wall (thickness indicated by arrowheads); sg - cysts with spermatogonia; bs - cysts with bipotential spermatocytes; aps - cysts with apyrene spermatocytes; eps - cysts with eupyrene spermatocytes; dg - degenerating cells (primary spermatocytes). Scale bars $=50 \mu \mathrm{m}$. 
in longitudinal or cross-sections of testes (Fig. 1F). During metamorphosis, spermatogenesis continues and results in a growing number of both eupyrene and apyrene sperm bundles that fill most of the space in TF (Figs $1 \mathrm{G}$ and $2 \mathrm{~L}-\mathrm{O}$ ).

During pupal development and after emergence in $G$. mellonella, Verson's cells and differentiating spermatogonia are still present in the testes, which indicates that spermatogenesis is not restricted to the larval/pupal period of development and possibly occurs throughout the entire lifespan of this species (Fig. 1G-H; see also Fig. 2 - table showing when during ontogenesis individual cell types appear during spermatogenesis). In G. mellonella, until the $2^{\text {nd }}$ day after pupation, the UVD lumen is clear, does not contain any visible particles and is only slightly stained in sections (Fig. 2P). On the $3^{\text {rd }}$ day, a viscous material appears in the UVD lumen, which is most likely a secretory product of the columnar epithelium that forms most of the inner layer of the wall of UVD (Fig. 2Q) (Bebas et al., 2002). This stage precedes sperm transfer from the testis and the first apyrene, which reach the UVD lumen on day 5 after pupation. Subsequently, the eupyrene appear in the UVD lumen immediately before adult emergence and are abundant in the UVD lumen in newly emerged (one-dayold) moths (Fig. 2R-S).

\section{Effects of diapause and fenoxycarb on testis morphology and germ cells}

The testes of $G$. mellonella do not fuse but remain separate regardless of the duration of diapause (Fig. 3A-C). Similarly, the testes of the larvae of $G$. mellonella treated with fenoxycarb do not fuse, and their morphology is very different (Fig. 3D-G). The changes are more pronounced after treatment as then the TF begin to occupy a smaller volume at the core of the testes, while the thickness of their walls increases, which is not observed in the testes of males in diapause (and control larvae - data not shown). Moreover, 28 days after treatment with fenoxycarb TF in sections are not arranged in the form a fan-like structure (typical for testes of larvae not in diapause and those in diapause) but are rather irregularly distributed (Fig. 3G).

Prolonged diapause results in both changes in the general morphology of spermatocyte containing cysts and their degeneration. In the TF of insects that have been in diapause for 60 days (D60) and 90 days (D90), all cysts appear to be smaller and irregular in shape compared to the rounder cysts in individuals that have been in diapause for only 30 days (D30) (Fig. 3A'-C'). A longer diapause is also associated with more prominent degenerative changes in a larger area in the proximal parts of TF. These observations indicate that the cells affected during diapause are the primary spermatocytes in cysts inside and around the zones of degeneration; primary spermatocytes are the most developmentally advanced cells that undergo degeneration. Similar to the individuals of $G$. mellonella that are in diapause and those treated with fenoxycarb, spermatogenesis only occurs until primary spermatocytes are formed. Seven days after application of fenoxycarb (F7) the cysts containing these cells were as shrunken as those in the testes of males that have been in diapause for 60 days (compare B' and D' in Fig. 3). However, some of these cysts (located proximally in the follicles) tend to be swollen. This swelling of cysts continued and 14 days after treatment with fenoxycarb the testes were full of round large cysts containing slightly stained germ cells and the borders between the individual cysts were still recognizable (Fig. 3E'). During the following week (21 days after the application of fenoxycarb - F21) the walls of some cysts, mainly those located centrally in TF, seemed to disappear. Thus, each contained a more or less dispersed cell mass (Fig. 3F'). In males evaluated 28 days after treatment (F28) the disintegration of the cysts was more advanced and the testes were full of germ cells (Fig. 3G'). The treatment of insects with fenoxycarb causes the degeneration of germ cells located in the proximal corner of their TF (as observed in males in diapause). In these insects, degenerating cells also form islet-like groups in the central and distal (apical) parts of some follicles, which was not observed in the testes of individuals in diapause (compare A'-C' and D'-G' on Fig. 3 ). These findings indicate that in fenoxycarb-treated larvae, not only do the differentiated primary spermatocytes die but also cells at earlier stages of spermatogenesis, such as bipotential spermatocytes, spermatogonia and even early gonial stem cells, if degeneration occurs throughout the distal region of the TF.

\section{Degenerative changes in the spermatocyte cysts in larvae in diapause and those treated with fenoxycarb}

Confocal microscope studies of whole testes stained with phalloidin-Texas Red, which binds to microfilaments in cytoplasm and is used to reveal cell shape, and the DNA fluorescent marker DAPI revealed numerous degenerative changes that appeared as a growing number of hole-like spots and spaces between the remaining germ cells in the TF of larvae in diapause and treated with fenoxycarb (Fig. 4A-J). These changes were also observed during TEM studies. Based on previous results concerning the effects of diapause on testis morphology (Polanska et al., 2005) we first focused on two zones in the proximal area of the TF; the border zone of degeneration (BZ) where morphological changes were restricted to only some cysts (while others were unchanged, indicating that in this zone, cells mature and die), and the most proximal zone (PZ) where degeneration of cysts was very prominent and included nearly all cysts. Cysts with apyrene and eupyrene primary spermatocytes were numerous in the BZ of D30 insects, and all of the spermatocytes were relatively tightly packed in the cysts and differed in morphology very little compared to those of 7-day-old larvae that were not in diapause (compare Fig. 4A' and Fig. 6C, D). Apyrene cells seemed to be slightly shrunken and less elliptical. For example, a large number of irregular spaces appeared between cells and the surface contact between cells was less. More prominent changes were observed in eupyrene cells of D30 insects, which seemed to be less compact and more irregular in shape and less dense in general; however, hetero-chromatization of their nuclei was obvious (compare Fig. 4A" and Fig. 6E, F). In addition, there were fewer mitochondria 

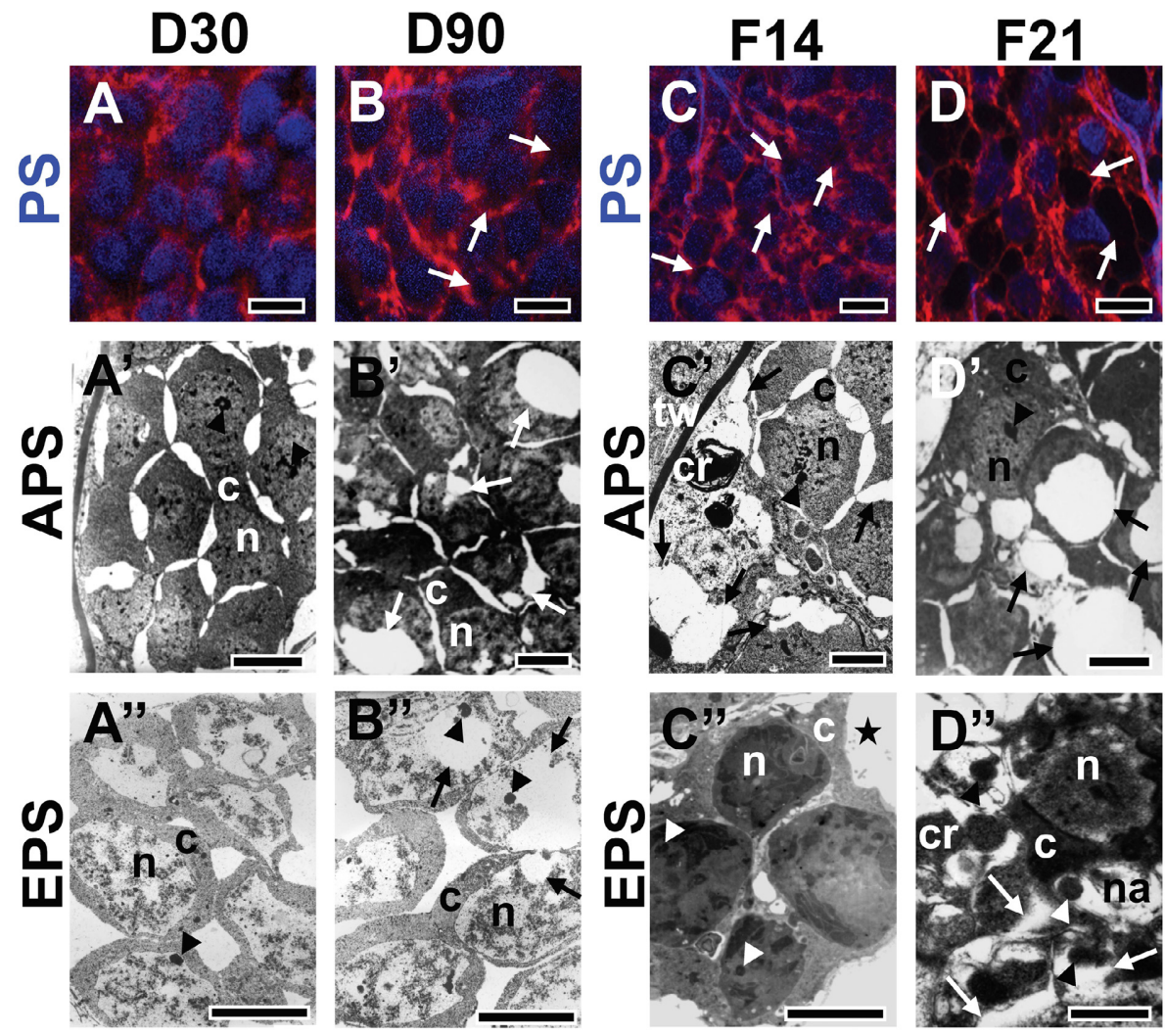

F28
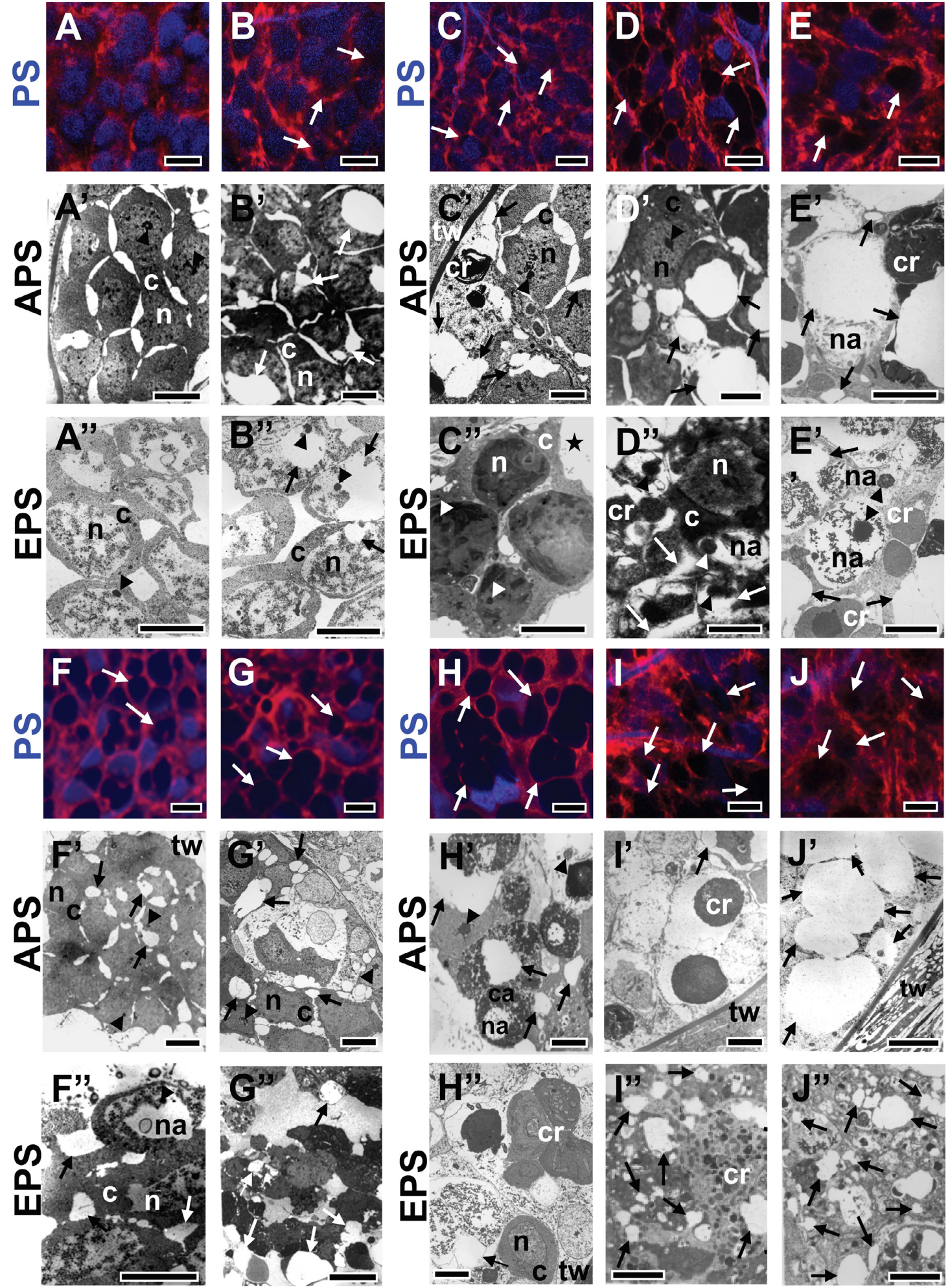

Fig. 4. Photographs of degenerative changes occurring in the proximal area of testicular follicles in last-instar larvae of $G$. mellonella, which have been in diapause for 30 (D30) and 90 (D90) days, or 7 (F7), 14 (F14), 21 (F21) or 28 days (F28) after treatment with fenoxycarb. The images in the first 3 rows are of the upper area with degenerating cysts (specified in the text as the border zone of degeneration, BZ), whereas the images in the last 3 rows are the areas of the testicular follicles located most proximally in the testicular follicles (specified as the proximal zone of degeneration, PZ). A-E and F-J - confocal microscope visualization of primary spermatocytes or their remnants (PS) in the $B Z$ and $P Z$, respectively, using an actin filament-binding probe - phalloidin (red) and a DNA probe - DAPI (blue); $A^{\prime}-E^{\prime}$ and F'-J' - TEM images are of primary apyrene spermatocytes or their remnants (APS) in BZ and PZ, respectively; A"-E" and F"-J" - TEM images are of primary eupyrene spermatocytes or their remnants (EPS) in BZ and PZ, respectively; $c$ and $n-c y t o p l a s m$ and nuclei of spermatocytes, respectively; na and ca - recognizable nuclear and cytoplasmic areas, respectively, after partial cell disintegration; $\mathrm{cr}$ cell remnants; tw - testis wall; spaces between the cells, hole-like areas and vesicle-like structures remaining after cell degeneration are indicated by arrows (white and black); pyknotic bodies in spermatocyte nuclei are indicated by arrowheads. Scale bars $=5 \mu \mathrm{m}$. 
and less membranous material in the cytoplasm of these cells. In individuals that had been in diapause for 90 days (D90) the nuclei in some apyrene and eupyrene cells had collapsed and the cytoplasm separated from the cell membrane resulting in large hole-like areas inside the cells (Fig. 4B', B'). Moreover, the general morphology of these cells, visualized by staining with fluorescent dyes, are similar to that of corresponding cells in the testes of F14 insects (compare B and C in Fig. 4). This was partially confirmed by TEM studies, which also revealed the collapse of nuclei in apyrene cells and numerous spaces between cells in each cyst, which accounted for the changes in cell volume (Fig. 4C'). However, in some cysts, single apyrene spermatocytes degenerated and only the remnants of these cells remained among the other cells. The morphology of eupyrene cells in the BZ of the follicles of F14 larvae differed completely from those of 7-day-old larvae in diapause and not in diapause (including larvae we used as controls for the JHA treatment - data not shown) (Fig. 4C"; also compare with Fig. $6 \mathrm{E}, \mathrm{F})$. The chromatin of these cells became very dense with numerous heteropyknotic spots (i.e., those that have an irregular shape) and many dense lamellar structures, which were rather randomly distributed in the nuclei. In F21 and F28 insects, both types of cysts degenerated. Apyrene spermatocytes completely collapsed and the dense remnants were located at the borders of cells of sister spermatocytes in particular cysts (Fig. 4D', E'). The course of degeneration of eupyrene cells differed because first the chromatin in F21 insects became strongly condensed, forming opaque material that subsequently (in F28 insects) seemed to disperse in the area that had previously contained nuclei (Fig. 4D", E").

In the PZ of TF, spermatocyte disintegration is more obvious than in BZ. The confocal microscopy studies showed that many cells in this area underwent significant shrinkage and died as early as day 30 of diapause (D30) (Fig. 4F). Nevertheless, in the D30 insects, recognizable apyrene and eupyrene spermatocytes were present in this area (Fig. 4F', F"). More obvious alterations were visible in the testes of the insects that remained in diapause for a further 60 days - i.e., for 90 days (D90) (Fig. 4G). Neither apyrene nor eupyrene cysts were present in the PZ of TF (Fig. 4G', G"). Thus, it was only by the presence of certain types of single cells (usually with an altered morphology) and by analogy with the spatial distribution of the cyst in $\mathrm{TF}$ of males not in diapause (apyrene situated more peripherally - close to the testicular wall - and eupyrene located more centrally), were we able to categorize all the visible remnants and determine their origin. In D90 insects, many apyrene spermatocytes disintegrated to form extracellular material of different densities between still-recognizable cells. Eupyrene spermatocytes in the same insects disappeared completely in this area, leading to an accumulation of multiple bodies with irregular shapes that differed from each other in terms of density.

The morphology of PZ after treatment of the insects with fenoxycarb was strongly affected and differed from the corresponding parts of TF in individuals in diapause.
Fourteen days after exposure (F14), the cytoplasm of apyrene cells became very dense, while the nuclei were mainly empty holes with sparse remnants of chromatin (Fig. 4H'). In the same area of the testes, most eupyrene spermatocytes seemed to form a condensate as their nuclei and cytoplasm stained darkly, but some cells disintegrated, leading to an accumulation of dispersed heterochromatic material (sometimes in the same cyst at different stages of spermatocyte disintegration) (Fig. 4H"). Three and four weeks after exposure to fenoxycarb (F21 and F28), the areas occupied by apyrene cells contained only strongly condensed, difficult to classify cells or ghost-like remnants of cells, indicating the previous positions of cells that had disappeared (Fig. 4I', J'). Morphological changes in eupyrene spermatocytes in the F21 and F28 insects differed from those of apyrene spermatocytes. Eupyrene cysts seemed to disintegrate, but their remnants were still present in the PZ in the form of vesicles with irregular surfaces or structures with varying electron densities; between these vesicles there were many small, hole-like spaces (Fig. 4 I", J").

\section{Cell death in the testes of larvae in diapause and those treated with fenoxycarb}

Application of the TUNEL technique in a previous analysis of larvae of $G$. mellonella in diapause revealed that degenerative changes in testes are similar to those occurring in programmed cell death (PCD) (Polanska et al., 2005). In the present study, PCD was recorded in germ cells in the testes of fenoxycarb-treated individuals. Nevertheless, while diapause affected only the cells located in the proximal area of TF (Fig. 5C, D), the cells affected by fenoxycarb treatment were irregularly distributed throughout TF (Fig. 5E, J). In the testes of fenoxycarb-treated males, dying cells were sometimes only present in the proximal area (as in insects in diapause) and in others only in the distal area. Moreover, there were more stained cells in the distal than in the proximal area (Fig. 5E, F, H). PCD was sometimes detected simultaneously in both regions, and less frequently in the middle-lateral area of TF (Fig. 5E, G). Cells stained by TUNEL in the proximal area of the TF of insects treated with fenoxycarb were of disintegrated cysts (as in insects in diapause), thereby confirming the results of the confocal microscopy and TEM studies (Fig. $4 \mathrm{G}$ " $-\mathrm{J}$ "). Conversely, the cells present in the distal area of $\mathrm{TF}$, even if stained, were usually organized into cysts (in F7, F14 and F21 insects). In the F28 insects, this cystic organization of germ cells disappeared; consequently, the TF were filled with masses of cells that were mostly stained, suggesting that these cells were destined to undergo cell death (Fig. 5I-J; also compare with Fig. 3G'). TEM analysis of the upper (distal) region of TF (occupied mostly by spermatogonia and primary bipotential spermatocytes see A and B in Fig. 1) in F28 insects revealed that the cells present there were strongly altered compared with cells in the same region in control insects; 7-day-old last instar larvae that were not-treated with fenoxycarb (compare Fig. 6A, B and Fig. 7) or treated with acetone (data not shown). In the F28 insects, late-spermatogonia/early-spermatocytes degenerated, and this process involved the disruption of 

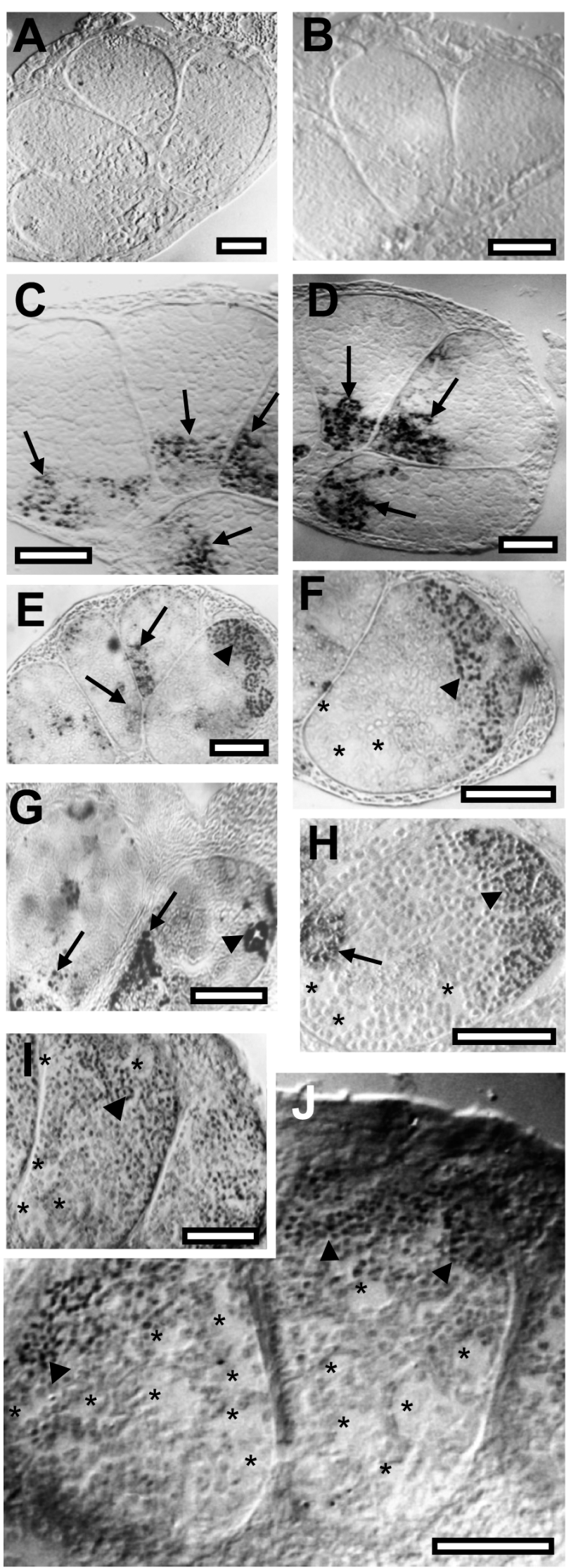
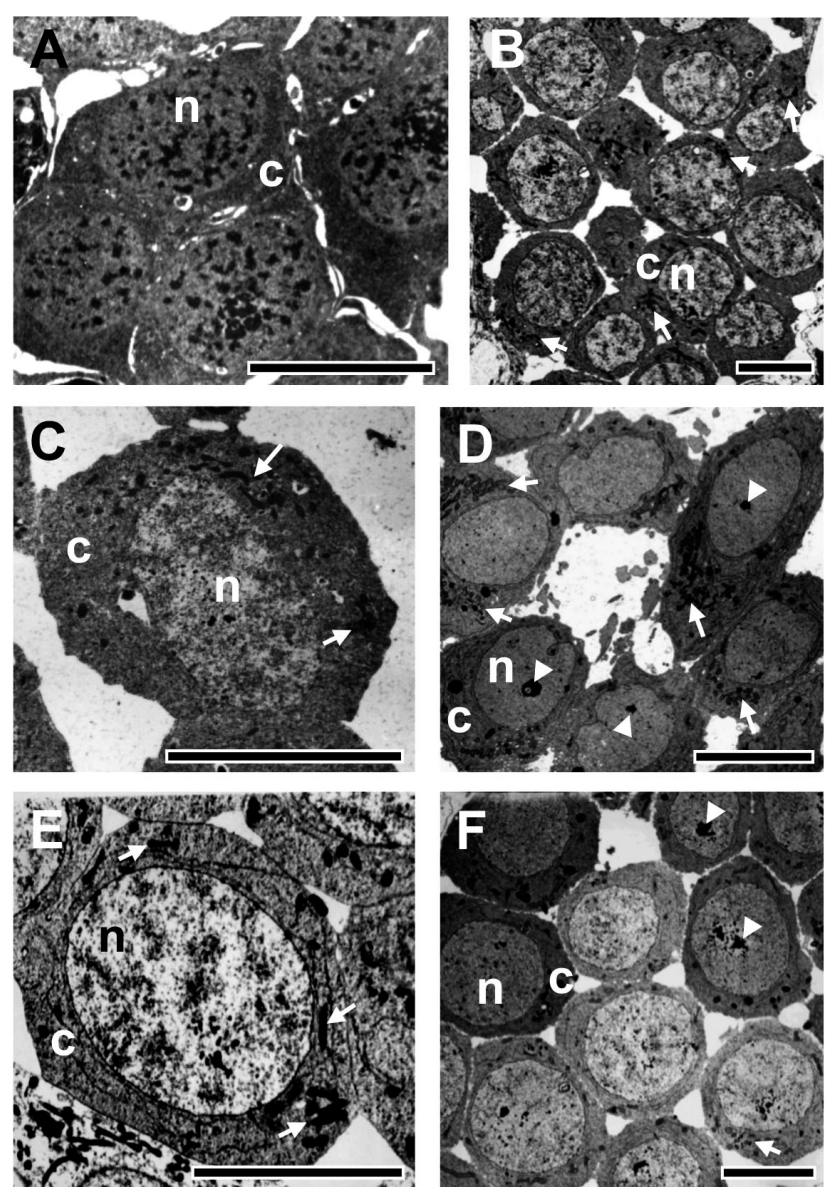

Fig. 6. Transmission electron microscopy (TEM) photographs of germ cells in the testes of seven-day-old G. mellonella last-instar larvae. A - late spermatogonia differentiating into spermatocytes; $\mathrm{B}$ - primary bipotential spermatocytes at the pachytene stage; C - early primary apyrene spermatocytes; D - primary apyrene spermatocytes in a cyst; $\mathrm{E}$ - early primary eupyrene spermatocytes with multiple membranes in the cytoplasm; $F$ - primary eupyrene spermatocytes in a cyst. c - cytoplasm; $\mathrm{n}$ - nucleus; mitochondria (or groups of mitochondria) indicated by white arrows; pyknotic bodies located in the nuclei of spermatocytes indicated by white arrowheads. Scale bars $=15 \mu \mathrm{m}$.

cells involving changes in the morphology of nuclei and cytoplasm, followed by the appearance of numerous vesicle-like structures and remnants of cells (which exhibit different densities), until the cells completely disappeared (Fig. 7A-F). In addition, the TF of F21 and, more frequently, F28 insects contained many randomly distributed areas that were devoid of cells (Fig. 5H-J). This result indicates that death and elimination of these cells occurred before the gonads were processed histochemically (i.e., during the first 3 weeks after treatment with fenoxycarb).

\section{DISCUSSION}

Differentiation of germ cells during spermatogenesis in G. mellonella resembles that described for the testes of

Fig. 5. Light microscopy photographs of longitudinal sections through the testes of last-instar larvae of $G$. mellonella examined using the TUNEL method. A - 7-day-old larvae not in diapase; B - negative control staining of a testis section of a last-instar larvae that have been in diapause for 90 days (sections incubated with label solution only, without terminal transferase, TdT); C-D - last-instar larvae that have been in diapause for 30 and 90 days, respectively; larvae on days 7: E, 14: F, 21: G-H, and 28: I-J after treatment with fenoxycarb. Accumulations of TUNEL-positive cells (stained black) in the proximal and distal areas of the testicular follicles are indicated by arrows and arrowheads, respectively. Areas devoid of cells are marked by asterisks. Scale bars $=50 \mu \mathrm{m}$. 

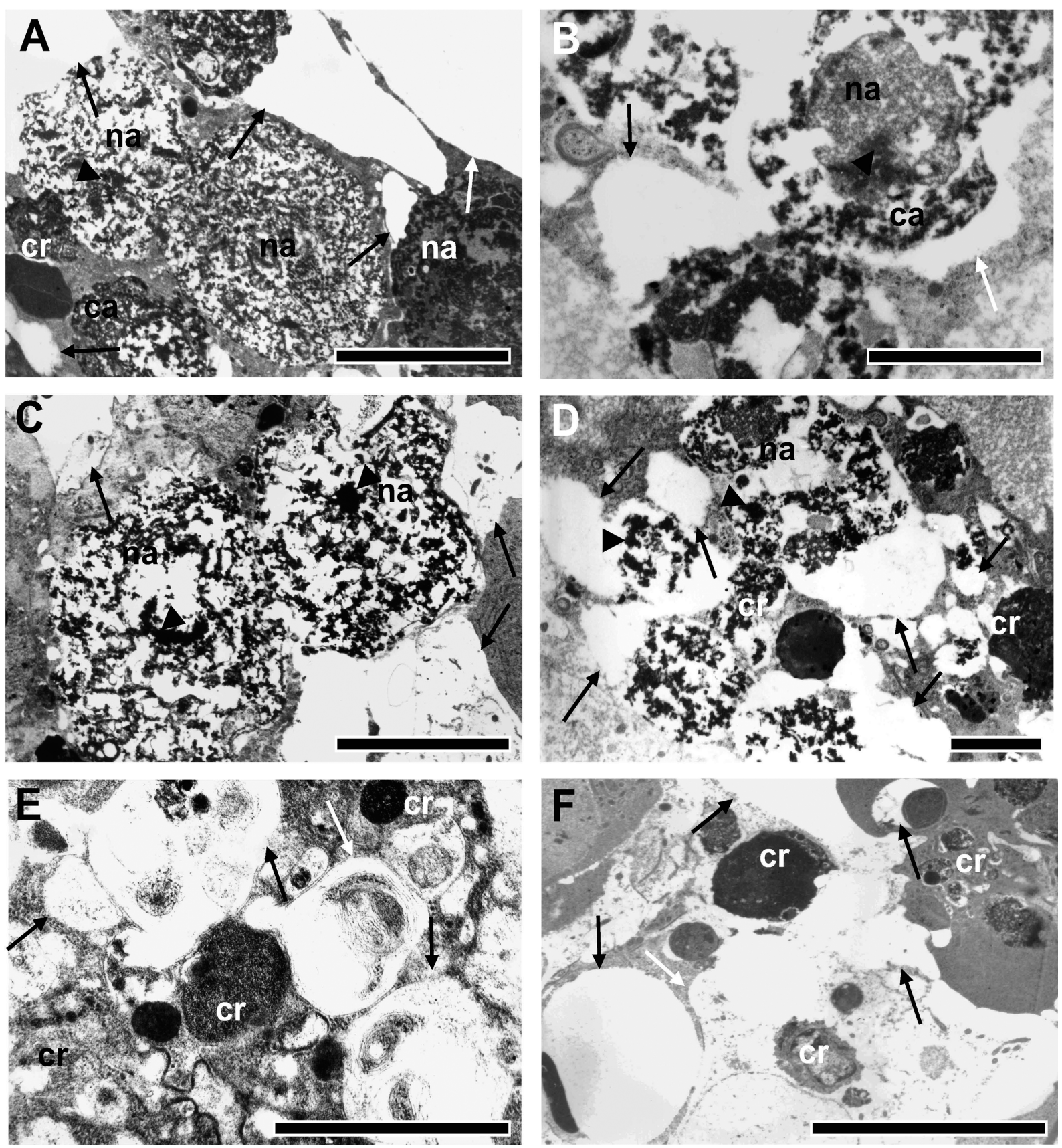

Fig. 7. TEM photographs of successive degenerative changes covering the distal area of testicular follicles in last-instar larvae of $G$. mellonella 28 days after treatment with fenoxycarb. A-B - degenerating, early primary spermatocytes with still-recognizable areas of cytoplasm and cell nuclei; C-D - spermatocytes at more advanced stages of degeneration - the position of the nucleus in degenerate cells is based on the presence of pyknotic bodies; E-F - mostly remnants of cells in the form of vesicles and bodies of different densities present among expanding spaces that appear when cells shrink and finally disappear. ca and na - still recognizable areas of cytoplasm and nuclei, respectively; cr - cell remnants; spaces between cells, hole-like areas and vesicle-like structures remaining after cell degeneration are indicated by arrows (white and black); pyknotic bodies in spermatocyte nuclei are indicated by arrowheads. Scale bars $=5 \mu \mathrm{m}$.

other moths. In last-instar larvae, the most distally located area of the TF is occupied by progenitors of somatic and germ-cells, which are organized in a germarium with a centrally located, single Verson's cell, which is the apical complex where the development of cysts with germ cells is organized, the basic units of testes in which spermatogenesis occur (Friedländer et al., 2005). In G. mellonella, as in other species, early spermatogenic cells (spermatogonia) in cysts undergo mitotic divisions, leading to the formation of easily distinguishable bipotential spermatocytes in the TF during the last larval stage. These cells occur in the testes of different families of Lepidoptera, e.g., Ectomyeolis ceratoniae (Leviatan \& Friedländer, 1979), Cydia pomonella (Friedländer \& Benz, 1982), Bombyx mori (Kawamura \& Sahara, 2002) and Spodoptera mauritia (Manogem \& Nair, 2013), with the possible exception of, e.g., Pieris brassicae (Tschudi-Rein \& Benz, 1990). Bipotential spermatocytes (if present) undergo differentiation into morphologically 

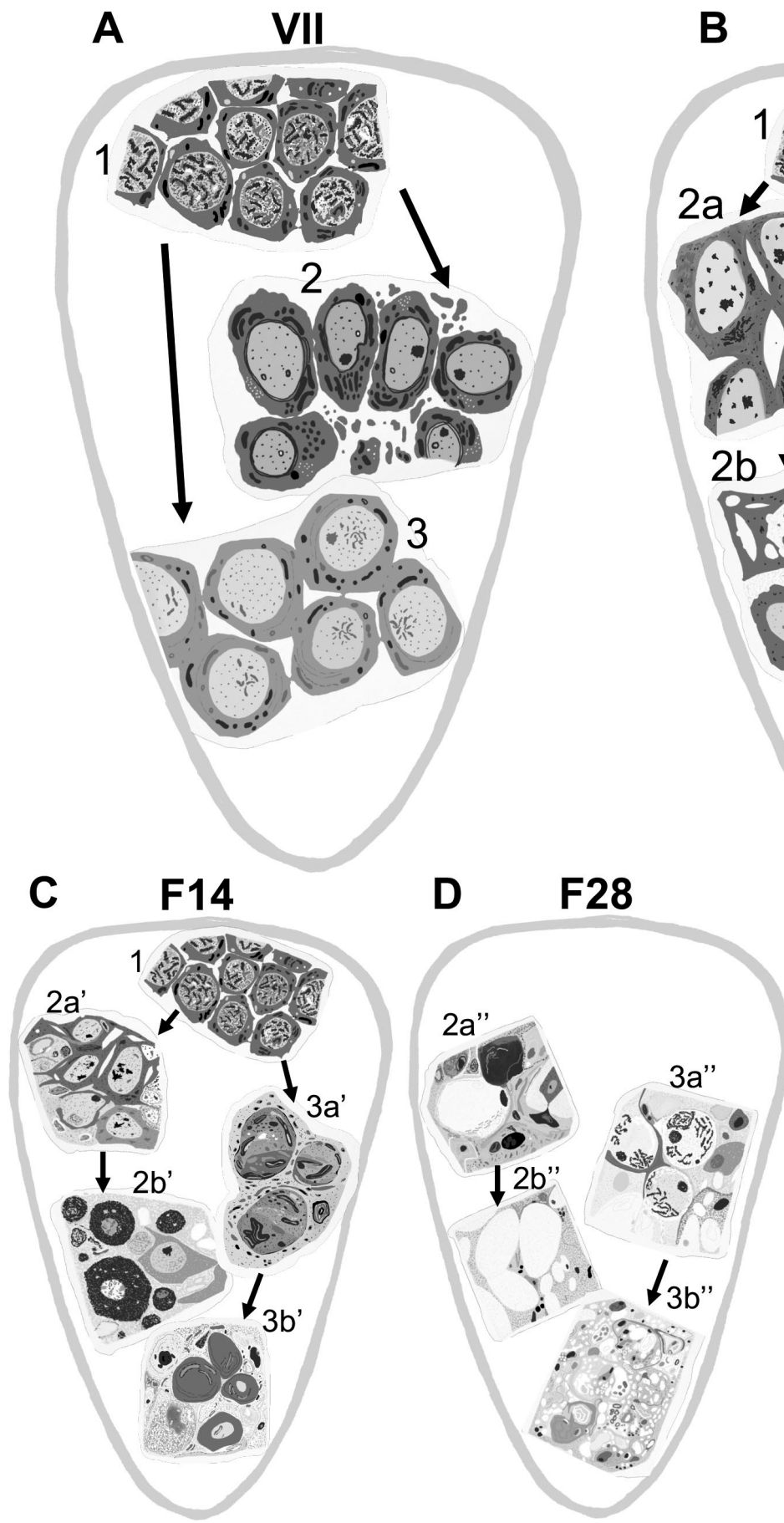

B D90
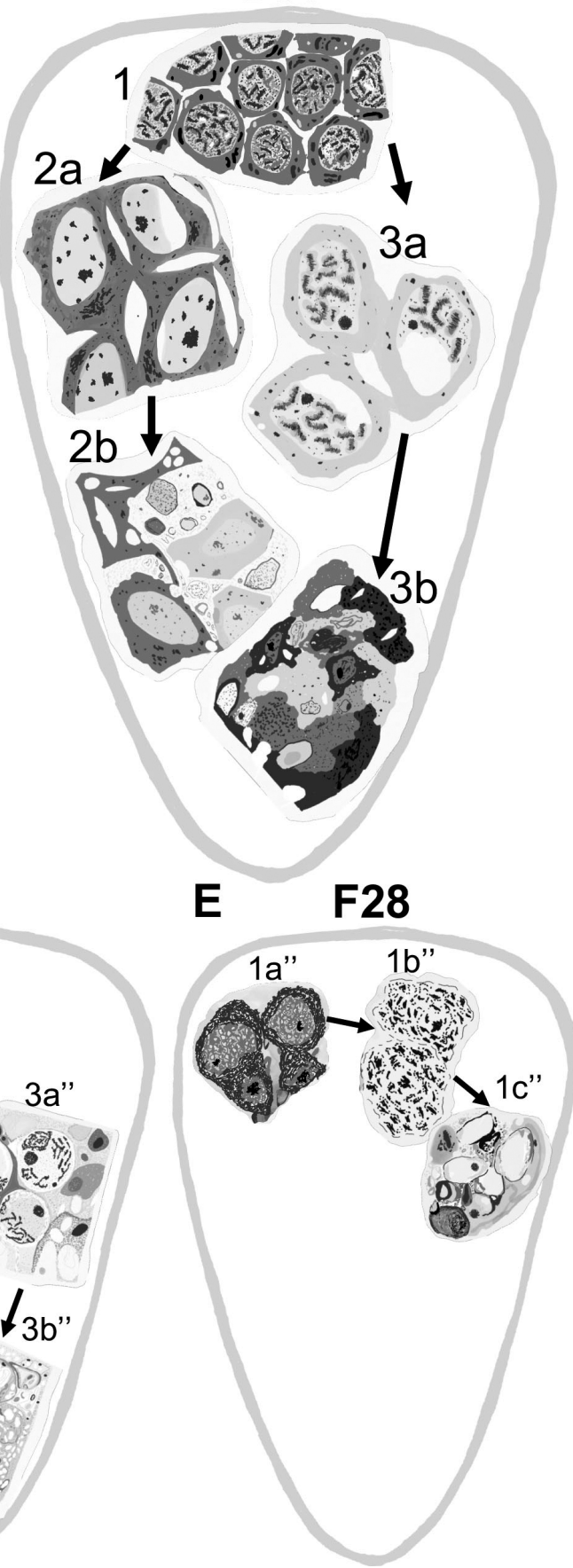

Fig. 8. Schematic drawings of testicular follicles to summarize the data on the changes occurring in the course of spermatogenesis in larvae of G. mellonella during normal development (as in Fig. 6), diapause (as in Fig. 4) and after treatment with fenoxycarb (as in Figs 4 and 7). A - in last $\left(7^{\text {th }}\right)$-instar larvae not in diapause (VII) cysts with bipotential spermatocytes (1) are produced continuously, followed by their differentiation into cysts with apyrene (2) and eupyrene (3) primary spermatocytes. B - individuals in diapause (for 90 days - D90), bipotential spermatocytes (1) still differentiate into apyrene and eupyrene spermatocytes; however, their morphologies change from cells that slightly smaller and have concave nuclei (2a and $3 a)$ to completely degenerate cells ( $2 b$ and $3 b)$. C - on day 14 after the application of fenoxycarb (F14) to the larvae, in the distal area of follicles, some cysts with bipotential spermatocytes are still present, which are soon to differentiate into apyrene and eupyrene spermatocytes, however, their morphologies change - apyrene cells (2a') shrink slightly, and later, their cytoplasm strongly condenses in the area surrounding the degenerate nucleus, finally taking the "black-donut-like" form ( $2 \mathrm{~b}$ '). In the same follicle, most eupyrene spermatocytes are affected: their nuclei first seem to swell and begin to become denser, and afterwards, some of these cells condense as a whole, forming dense remnants, while some of them seem to lose their integrity completely and fragment (3b'). D - in day 28 after treatment with fenoxycarb (F28), no bipotential spermatocytes were observed in the follicles, and nearly all apyrene spermatocytes containing cyst had disintegrated and only cell debris remained (2a"), which eventually disappeared, leaving hole-like areas (2b"). Eupyrene spermatocytes seem to go through a stage of "ghost-like" cells (3a") before complete disintegration. E - in F28, degeneration of less-advanced germ cells is also observed, e.g., early gonial cells located more distally in the follicle, which lose their complexity first resembling cells with a spongy structure, then turn into "ghost-like" cells that finally disintegrate leaving hole-like spots in the follicle lumen, surrounded by membranous and vesicular cell remnants. Black arrows determine the direction of changes that cells undergo when they degenerate. 
and functionally distinct apyrene and eupyrene cell lines. This seems to be the case for spermatogenesis in $G$. mellonella, as the largest zone in the testes of late instar larvae is occupied by primary apyrene and eupyrene spermatocytes. Interestingly, single cysts filled with secondary spermatocytes are also present in the testes of some individuals at this stage in the development of $G$. mellonella, which is also recorded for a few other species, such as Choristoneura fumiferana (Retnakaran, 1970), Diatraea grandiosella (Alexander \& Chippendale, 1973) and Spodoptera littoralis (Witalis \& Godula, 1993).

Metamorphosis strongly affects the morphology of the gonads in Lepidoptera. Paired larval testes fuse into a single gonad, which is first located in the upper part of the abdomen and then moves to a central position in the abdomen. The fusion process is followed by torsion, a morphological rearrangement of the testes leading to their final form. Torsion results in a significantly twisted TF that still retain their connections to one of the two vasa deferentia (the same one to which the TF was connected during the larval stage). Fusion and torsion is recorded in several different families of Lepidoptera and, as in G. mellonella, occurs in the early stages of metamorphosis (pre-pupal stage to the first days after pupation), e.g., in Ephestia kuehniella (Nowock, 1973), Manduca sexta (Reinecke et al., 1983), Spodoptera litura (Perveen et al., 2011) and Diatraea saccharalis (Pereira \& Santos, 2015).

In addition to the morphological changes in the testes, spermatogenesis results in the differentiation of new cell types in TF. In G. mellonella, the earliest stage at which elongated spermatids appear coincides with the fusion of the testes, whereas spermatozoa appear in the first days after pupation, which most likely coincides with final stages of the torsion process (Witalis \& Godula, 1993). In many moths, spermatogenesis, including spermiogenesis, is usually completed by the end of metamorphosis; thus, the testes of pharate adults are filled with fully developed and ready-to-release spermatozoa (Friedländer et al., 2005). The occurrence of spermatogenesis in adults (including the differentiation of early gonial cells) is not common in Lepidoptera, but is recorded in at least some species: Calpodes ethlius (Lai-Fook, 1982), Methona themisto (CorsatoAlvarenga et al., 1987), Polygonia c-aureum (Hiroyoshi, 1999), Euptoieta hegesia (Mancini \& Dolder, 2004) and Diatraea saccharalis (Pereira \& Santos, 2015). However, it must be noted that the timetable of spermatogenesis is rather species-specific because it ends at different times during ontogeny even in closely related species, sometimes it ceases in pupae [e.g., in the Noctuid moth: $S$. littoralis (Witalis \& Godula, 1993)] and sometimes it continues into adult life [e.g., in the Noctuid moth: S. litura (Sridevi et al., 1989); for a review, see (Friedländer et al., 2005)]. Thus, such differences in the timing of spermatogenesis are also likely to occur in pyralids, as spermatogenesis in Ostrinia nubilalis (Chaudhury \& Raun, 1966) ceases in the pupal stage, and in contrast spermatocytes occur in the testes of young adults of Achroia grisella (Fernandez-Winckler
\& da Cruz-Landim, 2008) and G. mellonella, as reported here.

There is a temporal separation in the transfer of apyrene and eupyrene sperm from testes to the UVD prior to eclosion in G. mellonella. This also occurs in B. mori (Katsuno, 1977a), Lymantria dispar (Giebultowicz \& Joy, 1992; Giebultowicz et al., 1997) and S. littoralis (Bebas et al., 2001); however, its role remains unknown. Because sperm transfer to the UVD is a complex process involving interactions between the cyst cells of sperm bundles and the epithelial cells of testes (forming the cellular membrane between the TF and UVD), it is suggested that apyrene bundles somehow initiate this process for eupyrene bundles (Gvakharia et al., 2003). This explanation is strongly supported by the features of the transfer of sperm from the testis to the UVD in adults of E. kuehniella (Riemann et al., 1974), B. mori (Katsuno, 1977b), S. littoralis (Bebas et al., 2001) and S. litura (Seth et al., 2002), which is described as a repeatedly occurring event, initiated daily by apyrene sperm transfer.

In insects, the way morphological changes in the testis and course of spermatogenesis occur are strongly affected by diapause. In G. mellonella, as in other Lepidoptera that diapause in the larval stage, the testes do not fuse regardless of the duration of such dormancy. It seems to be an effect of the hormonal milieu (crucial to maintaining diapause) that is manifested by a high level of juvenile hormones and a low level of ecdysteroids in the haemolymph. In this context, the role of ecdysteroids is widely discussed, as an elevated level of these hormones at the time of metamorphosis in both haemolymph and testes is strongly correlated with their fusion in Heliothis virescens (Meola \& Loeb, 1995), E. kuehniella (Nowock, 1973; Bouzeraa \& Soltani-Mazouni, 2014) and S. littura (Perveen, 2011; Perveen et al., 2011); see also (Meola et al., 1997) and publications cited therein. Moreover, the treatment of $C$. pomonella males with ecdysteroid agonists that mimic the activities of these hormones also induces testis fusion (Friedländer \& Brown, 1995). Nevertheless, very little is known about how juvenoids (if they are involved) affect this process in Lepidoptera. Here, we applied fenoxycarb to larvae of $G$. mellonella not in diapause, and the lack of testicle fusion after such treatment, was the only effect analogous to the changes in testicular morphology observed in the insects in diapause. Other changes in the internal structure of testes were very prominent and aberrant. As in G. melloenlla treated with fenoxycarb, similar effects in terms of hypertrophy of the testes wall and a reduced number of germ cells are reported for Blattella germanica treated with pyriproxyfen (another JHA) (Fathpouri et al., 2007). Although the distortion of the TF position in the testes resembles the internal structure of larval and adultoid testes that develop after treatment of young larvae and pupae of Corcyra cephalonica with the JHAs: hydroprene and altozar (ZR-0512) (Deb \& Chakravorty, 1981).

Although relatively little is known about the effects of JH on the development of testes, its effect on spermatogenesis is much better documented. As early as 1936, Wiggles- 
worth demonstrated that allatectomy does not affect spermatogenesis in adult Rhodnius prolixus (Wigglesworth, 1936). Subsequently, other authors showed only a slight hastening of spermatogenesis in allatectomized larvae of B. mori (Fukuda, 1944), Periplaneta americana (Blaine \& Dixon, 1970) and E. kuehniella (Nowock, 1973). In the allatectomized larvae of Actias selene, due to the premature decline in the $\mathrm{JH}$ titer, an earlier elongation of spermatid nuclei is reported (Friedländer et al., 1981). Other authors have shown that exposure of preadult stages of $B$. mori to exogenous JH or its analogues (JHA) (Takeuchi, 1969), $R$. prolixus (Dumser \& Davey, 1974), P. americana (Blaine \& Dixon, 1976), S. littoralis (Gelbic \& Metwally, 1981) and $C$. pomonella (Friedländer, 1982) effectively inhibits this process; a similar effect is reported in the penultimate instars of Locusta migratoria with implanted corpora allata (Cantacuzene, 1970) and in adults of Cybister tripunctatus treated with JH (Zahera \& Tembhare, 2016). The latter occurs in larvae of $G$. mellonella in diapause [at that time the haemolymph level of JH is significantly higher (Smietanko et al., 1989)], and in larvae treated with fenoxycarb.

Based on previous and current findings, we propose that spermatocytes in $G$. mellonella are primary cells that die during prolonged diapause (Polanska et al., 2005). Our observations are also confirmed by data for the lepidopteran C. pomonella, which is probably the most extensively investigated species in terms of the effects of diapause and juvenoids on male germ cells. In the last larval stage, when diapause commences in this species, spermatogenesis terminates at the spermatocyte stage (Friedländer \& Benz, 1982). However, this concerns only eupyrene cells because no apyrene spermatocytes were found in testes at this stage of development. In C. pomonella, direct and reversible effects of juvenile hormone on spermatogenesis in individuals in diapause and not in diapause are also described. Treatment of larvae not in diapause with Altosid ${ }^{\circledR}$ (containing juvenoid methoprene as an active ingredient) causes a discontinuity in spermatogenesis and lysis of spermatocytes, whereas in larvae already determined to enter diapause from which the corpora allata is removed spermatocyte lysis ceases and spermatogenesis is resumed (Friedländer, 1982).

According to some studies, the influence of juvenile hormone on spermatogenesis is rather indirect and involves reducing the level of ecdysteroids in the blood, which increases the rate of germ cell mitotic divisions (Dumser \& Davey, 1974, 1975a, b). This may be due to the inhibitory effect of $\mathrm{JH}$ on the release of prothoracicotropic hormone (PTTH) and a reduction in ecdysteroid synthesis in the prothoracic glands as described in B. mori (Sakurai et al., 1989; Takaki \& Sakurai, 2003) and M. sexta (Rountree \& Bollenbacher, 1986). This interpretation, however, is unlikely to be correct if as in some insects, the testes are an endogenous source of ecdysteroid under the control of the testes' ecdysiotropic peptides (TE) and because the amino acid structures of TE differ markedly from those of PTTHs (Loeb et al., 1998, 2001). Concomitantly, there are no data indicating that $\mathrm{JH}$ affects TE production. Moreover, the ac- tion of $\mathrm{JH}$ is pleiotropic and can change temporarily even in the same instar of a given species (Gruetzmacher et al., 1984; Hartfelder, 2000). Another interpretation assumes that the modulation of $\mathrm{JH}$ in germ and/or somatic cells in testes occurs in response to the ecdysteroids already present in the blood. According to Friedländer and coworkers (2005), in the absence/presence of $\mathrm{JH}$, different isoforms of ecdysteroid receptors are expressed, which result in cells differing in their sensitivity to these hormones (Riddiford et al., 2001, 2003; Sullivan \& Thummel, 2003). This is more likely what happens in G. mellonella as the degeneration of germ cells in testes during diapause coincides not only with high levels of juvenile hormone but also reduced, but significant, levels of ecdysteroids in the haemolymph (Mikolajczyk \& Cymborowski, 1993). This phenomenon coincides in $G$. mellonella with the relatively high level of PTTH in the brains of larvae in diapause, which exhibit in vitro high prothoracicotropic activity (Muszynska-Pytel et al., 1993).

In insects, the changes in male germ cell morphology caused by diapause and juvenile hormone or its analogs are rarely recorded in TEM studies. Moreover, they have species-specific characteristics, e.g., when $C$. pomonella is in diapause, only eupyrene spermatocytes are recorded degenerating because there are no apyrene spermatocytes in the testes of individuals in diapause (Friedländer \& Benz, 1982; Friedländer \& Brown, 1995). Thus, these data cannot be directly compared with the results obtained for $G$. mellonella. However, one general rule seems to exist; the disintegration of germ cells in testes of males in diapause occurs along the longitudinal axis of TF and in the different populations of cells (depending on the species) that are most abundant in the most proximal part of TF. This is based on studies on Lepidoptera (including G. mellonella) (Alexander \& Chippendale, 1973; Polanska et al., 2005) and at least one species of Coleoptera (Friedländer $\&$ Scholtz, 1993). The number of cells (cysts) that disintegrate depends on the duration of diapause, because it affects a large area of TF in males of $G$. mellonella that have been in diapause for a long time (Polanska et al., 2005). We thought that an analysis of the morphology of cells in BZ would reveal common features of the beginning of the process of cell degeneration and it would be similar in BZ in all individuals in diapause regardless of the time that has elapsed since the beginning of diapause. However, this hypothesis lacks support. Unexpectedly, the cells in BZ in individuals that have been in diapause for a long time showed more changes (degenerated) than those in individuals that have been in diapause for a short period of time. The same situation occurs in insects treated with fenoxycarb: spermatocyte cysts in BZ of F28 insects were the most affected. One explanation for this is that some diapause-accompanying factors and the application of JHA alter only spermatocytes at a particular stage of differentiation and these are the cells that gradually degenerate. Based on this finding, the large number of degenerate cells in the proximal area of TF is a consequence of their being destined to die, which is determined early in 
diapause (most likely when diapause is initiated). In turn, the results obtained for fenoxycarb-treated males indicate that a juvenizing factor could be involved in this process. However, it is postulated that spermatogenesis in Lepidoptera continues throughout larval and pupal diapause but not adult diapause (Friedländer, 1997; Hiroyoshi et al., 2017). Thus, the number of newly differentiated spermatocytes should increase in TF if these cells do not become destined to die during diapause. To solve these problems, a detailed analysis of the rate of spermatogenesis during diapause in $G$. mellonella is required.

Here, we have revealed that both diapause and the treatment of larvae with fenoxycarb cause PCD in testes. PCD as a mechanism of germ cell elimination from insect testes is recorded in Lepidoptera and Isoptera. In the latter, apoptosis of male germ cells is described as a naturally occurring process accompanying soldier differentiation (a caste that does not reproduce) in Reticulitermes labralis and affects mainly spermatogonia (Su et al., 2015). Conversely, apoptosis in the testes of differentiating organisms occurs at a much lower rate and includes spermatocytes. It is important to note that soldier caste differentiation in termites is generally associated with a much higher JH titer in the haemolymph than in reproductive tissues and can be induced by the application of juvenile hormone analogues (e.g., pyriproxyfen) to these insects (Cornette et al., 2008). These findings may lead to the hypothesis that depending on the juvenoid level, different populations of germ cells acquire competence that directs them to die. Thus, the dose of fenoxycarb that induced extra moults in all the larvae in the population investigated was high enough to induce PCD in both spermatogonia and spermatocytes at different stages of maturity, whereas diapause was associated with a level of juvenoids that may cause PCD only in spermatocytes. The effect of diapause on PCD in the testes of Lepidoptera is reported for Agrius alcinou and A. convolvuli (Kubo-Irie et al., 1999; Shimoda et al., 2007). In both these species, however, the study was done using pupae, the stage at which these species diapause, which may have resulted in the significant differences noted in the stages at which germ cells undergo degeneration, e.g., spermatids, were not present in the testes of $G$. mellonella in diapause. In addition, cell death was noted in the pupae of $A$. alcinou and $A$. convolvuli. There are no records in the literature of PCD caused by JHA occurring in the testes of Lepidoptera. Thus, our data are the first demonstration of this phenomenon and support the hypothesis that fenoxycarb can be used to mimic the action of JH and IGR strongly alters male gonad physiology, causing germ cell death at different stages of differentiation.

In summary, our observation lead to the conclusion that in the testes of $G$. mellonella, the only cells affected by diapause are primary spermatocytes, which based on their morphology can be classified as either apyrene or eupyrene. Both of these cells degenerate but the course of their degeneration differs. Treatment of larvae with fenoxycarb results in many similar effects to those observed during diapause, mainly immediately after its application. However, the longer the time that has elapsed from the application of fenoxycarb the stronger the effects on the morphology of the testes and spermatogenesis (main effects depicted in Fig. 8).

ACKNOWLEDGEMENTS. The authors thank T.A. Szczuka for help with insect rearing and M. Kuras for help with image analysis, sharing reagents and advice. This study was supported by the Polish National Science Centre (NCN) grant No. N N303 803340 to BC and partially by NCN grant No. 2013/11/B/NZ4/03310 to PB.

\section{REFERENCES}

Alexander B.R. \& Chippendale G.M. 1973: Spermatogenesis of the southwestern corn borer, Diatraea grandiosella. 1. Comparison of rates in prediapause and nondiapause larvae. - Ann. Entomol. Soc. Am. 66: 747-752.

Bebas P., Cymborowski B. \& Giebultowicz J.M. 2001: Circadian rhythm of sperm release in males of the cotton leafworm, Spodoptera littoralis: In vivo and in vitro studies. - J. Insect Physiol. 47: 859-866.

Bebas P., Maksimiuk E., Gvakharia B., Cymborowski B. \& GieBULTowicz J.M. 2002: Circadian rhythm of glycoprotein secretion in the vas deferens of the moth, Spodoptera littoralis. BMC Physiol. 2: 1-10.

Belles X. \& Maestro J.L. 2005: Endocrine peptides and insect reproduction. - Invertebr. Reprod. Dev. 47: 23-37.

BLAINE W.D. \& DixON S.E. 1970: Hormonal control of spermatogenesis in the cockroach, Periplaneta americana (L.). - Can. J. Zool. 48: 283-287.

Blaine W.D. \& Dixon S.E. 1976: Testicular development in the cockroach, Periplanata americana (L). - Proc. Entomol. Soc. Ont. 106: 60-65.

Bouzeraa H. \& Soltani-Mazouni N. 2014: Comparative effects of two moulting hormone agonists (methoxyfenozide and tebufenozide) on the Mediterranean flour moth Ephestia kuehniella Zeller (Lepidoptera: Pyralidae): Ecdysteroids amounts of testes and reproductive events. - World Appl. Sci. J. 31: 1903-1910.

CAntacuzene A.M. 1970: Altérations de la spermiogenèse de Locusta migratoria migratorioïdes après implantation de corps allates et après irradiation. - Z. Zellforsch. Mikrosk. Anat. 103: 351-364.

Chaudhury M.F.B. \& Raun E.S. 1966: Spermatogenesis and testicular development of the European corn borer, Ostrinia $n u$ bialis (Lepidoptera: Pyraustidae). — Ann. Entomol. Soc. Am. 59: 1157-1159.

Chippendale G.M. \& Alexander B.R. 1973: Spermatogenesis of the southwestern corn borer. Diatraea grandiosella. 2. Resumption in diapause larvae. - Ann. Entomol. Soc. Am. 66: 761-768.

Cholodkovsky N. 1880: Über die Hoden der Schmetterlinge. Zool. Anz. 3: 115-117.

Cornette R., Gotoh H., Koshikawa S. \& Miura T. 2008: Juvenile hormone titers and caste differentiation in the damp-wood termite Hodotermopsis sjostedti (Isoptera, Termopsidae). - J. Insect Physiol. 54: 922-930.

Corsato-Alvarenga L.B.F., Cestari A.N. \& Ribeiro A.F. 1987: Eupyrene and apyrene spermatogenesis in Methona themisto (Lepidoptera: Ithomiidae). — Braz. J. Genet. 10: 655-671.

Cymborowski B. 2000: Temperature-dependent regulatory mechanism of larval development of the wax moth (Galleria mellonella). — Acta Biochim. Pol. 47: 215-221. 
Dallai R. 2014: Overview on spermatogenesis and sperm structure of Hexapoda. - Arthr. Struct. Dev. 43: 257-290.

Dallai R., Gottardo M. \& Beutel R.G. 2016: Structure and evolution of insect sperm: New interpretations in the age of phylogenomics. - Annu. Rev. Entomol. 61: 1-23.

Deb D.C. \& Chakravorty S. 1981: Effect of a juvenoid on the growth and differentiation of the ovary of Corcyra cephalonica (Lepidoptera). - J. Insect Physiol. 27: 103-111.

DRECKTRAH H.G. 1966: Morphology and histology of the internal reproductive systems of the European corn borer, $\mathrm{Os}_{-}$ trinia nubilalis (Hübner). Unpublished Results. In Digital Repository. Iowa State University of Science and Technology, Ames, p. 13, URL: https://lib.dr.iastate.edu/cgi/viewcontent. cgi?article $=6309 \&$ context $=$ rtd

DUMSER J.B. 1980: The regulation of spermatogenesis in insects. - Annu. Rev. Entomol. 25: 341-369.

Dumser J.B. \& Davey K.G. 1974: Endocrinological and other factors influencing testis development in Rhodnius prolixus. Can. J. Zool. 52: 1011-1022.

DuMSER J.B. \& DAVEY K.G. 1975a: The Rhodnius testis: hormonal effects on germ cell division. - Can. J. Zool. 53: 1682-1689.

Dumser J.B. \& Davey K.G. 1975b: The Rhodnius testis: hormones, differentiation of the germ cells, and duration of the molting cycle. - Can. J. Zool. 53: 1673-1681.

Fathrouri H., Noori A. \& Zeinali B. 2007: Effects of a juvenoid pyriproxyfen on reproductive organ development and reproduction in German Cockroach (Dictyoptera: Blattellidae). Iran. J. Sci. Technol. (A) 31: 89-98.

Fernandez-Winckler F. \& DA CRUZ-Landim C. 2008: Spermatogenesis chronology in Achroia grisella Fabricius (Lepidoptera, Pyralidae) comparing eupyrene and apyrene spermiogenesis. - Anim. Biol. 58: 1-11.

FRIEDLÄNDER M. 1982: Juvenile hormone and regulation of dichotomous spermatogenesis during the larval diapause of the codling moth. - J. Insect Physiol. 28: 1009-1012.

FRIEDLÄNDER M. 1997: Control of the eupyrene-apyrene sperm dimorphism in Lepidoptera. - J. Insect Physiol. 43: 1085-1092.

FRIEDLÄNDER M. \& BENZ G. 1982: Control of spermatogenesis resumption in post-diapausing larvae of the codling moth. $-J$. Insect Physiol. 28: 349-355.

FrIEDLÄNDER M. \& BRown J.J. 1995: Tebufenozide (Mimic), a non-ecdysteroidal ecdysone agonist, induces spermatogenesis reinitiation in isolated abdomens of diapausing codling moth larvae (Cydia pomonella). - J. Insect Physiol. 41: 403-411.

FRIEDLÄNDER M. \& REYNOLDS S.E. 1992: Intratesticular ecdysteroid titres and the arrest of sperm production during pupal diapause in the tobacco hornworm, Manduca sexta. - J. Insect Physiol. 38: 693-703.

FrIEDLÄNDER M. \& SCHOLTZ C.H. 1993: Two different patterns of interrupted spermatogenesis in winter diapause and summer quiescence in the desert beetle, Omorgus freyi. - J. Morphol. 218: $347-358$.

Friedländer M., Jans P. \& Benz G. 1981: Precocious reprogramming of eupyrene-apyrene spermatogenesis commitment induced by allatectomy of the penultimate larval instar of the moth Actias selene. - J. Insect Physiol. 27: 267-269.

FriedLÄNDER M., JEShTADI A. \& REYNOLDS S.E. 2001: The structural mechanism of trypsin-induced intrinsic motility in Manduca sexta spermatozoa in vitro. - J. Insect Physiol. 47: 245-255.

FRIEDLÄNDER M., SETH R.K. \& REYNOLDS S.E. 2005: Eupyrene and apyrene sperm: Dichotomous spermatogenesis in Lepidoptera. - Adv. Insect Physiol. 32: 206-308.

FUKUDA S. 1944: The hormonal mechanism of larval molting and metamorphosis in the silkworm. - J. Fac. Sci. Univ. Tokyo 6: $477-532$.
Gelbic I. \& Metwally M.M. 1981: Changes in the development of male germinal cells of Spodoptera littoralis caused by the effects of juvenoids (Lepidoptera, Noctuidae). - Acta Entomol. Bohemoslov. 78: 10-17.

Giebultowicz J.M. \& Joy J.E. 1992: Ontogeny of the circadian system controlling release of sperm from the insect testis. $-J$. Biol. Rhythm. 7: 203-212.

Giebultowicz J.M., Weyda F., Erbe E.F. \& Wergin W.P. 1997: Circadian rhythm of sperm release in the gypsy moth, Lymantria dispar: ultrastructural study of transepithelial penetration of sperm bundles. - J. Insect Physiol. 43: 1133-1147.

Gruetzmacher M.C., Gilbert L.I., Granger N.A., Goodman W. \& BollenBacher W.E. 1984: The effect of juvenile hormone on prothoracic gland function during the larval-pupal development of Manduca sexta: An in situ and in vitro analysis. $-J$. Insect Physiol. 30: 331-340.

Gvakharia B.O., Bebas P., Cymborowski B. \& Giebultowicz J.M. 2003: Disruption of sperm release from insect testes by cytochalasin and [beta]-actin mRNA mediated interference. Cell. Mol. Life Sci. 60: 1744-1751.

HAPP G.M. 1992: Maturation of the male reproductive system and its endocrine regulation. - Annu. Rev. Entomol. 37: 303-320.

HARTFELDER K. 2000: Insect juvenile hormone: from "status quo" to high society. - Braz. J. Med. Biol. Res. 33: 157-177.

Hiroyoshi S. 1999: Eupyrene and apyrene spermatogenesis in the Asian comma butterfly, Polygonia c-aureum (Lepidoptera: Nymphalidae). - Entomol. Sci. 2: 297-305.

Hiroyoshi S.,Yoshimura J., Iwabuchi K., Reddy G.V.P. \& MitSUHASHI J. 2017: Effects of pre-overwintering conditions on eupyrene and apyrene spermatogenesis after overwintering in Polygonia c-aureum (Lepidoptera: Nymphalidae). - J. Insect Physiol. 100: 1-8.

Hunter E.E., Maloney P. \& Bendayan M.S. 1993: Practical Electron Microscopy: A Beginner's Illustrated Guide. Cambridge University Press, New York, 173 pp.

JoNES J.A. 1973: Post-embryonic development of the reproductive system of the European corn borer, Ostrinia nubilalis (Hübner). Unpublished Results. In Digital Repository. Iowa State University of Science and Technology, Ames, p. 168, URL: https://lib.dr.iastate.edu/cgi/viewcontent.cgi?referer=https:// www.google.com/\&httpsredir=1\&article $=5946$

Jones J.A., Guthrie W.D. \& Brindley T.A. 1984: Postembryonic development of the reproductive system of male European corn borers, Ostrinia nubilalis (Lepidoptera: Pyralidae). - Ann. Entomol. Soc. Am. 77: 155-164.

KATSUNO S. 1977a: Studies on eupyrene and apyrene spermatozoa in the silkworm, Bombyx mori L. (Lepidoptera: Bombycidae). 1. The intratesticular behaviour of the spermatozoa at various stages from the 5th-instar to the adult. - Appl. Entomol. Zool. 12: $142-153$.

Katsuno S. 1977b: Studies on eupyrene and apyrene spermatozoa in the silkworm, Bombyx mori L. (Lepidoptera: Bombycidae): IV. The behaviour of the spermatozoa in the internal reproductive organs of female adults. - Appl. Entomol. Zool. 12: $352-359$.

KaWAmura N. \& Sahara K. 2002: In vitro cultivation of spermatocysts to matured sperm in the silkworm Bombyx mori. Dev. Growth Differ. 44: 273-280.

KLOWDEN M.J. 2004: Endocrine regulation of insect reproduction. In Capinera J.L. (ed.): Encyclopedia of Entomology. Kluwer Academic Publishers, Dordrecht, pp. 765-769.

KLOWDEN M.J. 2013: Reproductive systems. In Klowden M.J. (ed.): Physiological Systems in Insects. Academic Press, London \& San Diego, pp. 198-251. 
Kubo-Irie M., Ohta K., Meguro T., Nakazawa T. \& Mohri H. 1999: Morphological evidence that spermatogenic cells undergo apoptosis within testis of diapausing swallowtail pupa (Atrophaneura alcinous). - J. Exp. Zool. 283: 194-201.

LAChance L.E. \& Olstad G. 1988: Spermiogenesis of eupyrene sperm in prepupae, pupae, and adults of Heliothis virescens (Lepidoptera: Noctuidae): an ultrastructural study. - Ann. Entomol. Soc. Am. 81: 292-300.

LAI-FoOK J. 1982: Testicular development and spermatogenesis in Calpodes ethlius Stoll (Hesperiidae, Lepidoptera). — Can. J. Zool. 60: 1161-1171.

LEVIATAN R. \& FriedLÄNDER M. 1979: The eupyrene-apyrene dichotomous spermatogenesis of Lepidoptera. 1. The relationship with postembryonic development and the role of the decline in juvenile hormone titer toward pupation. - Dev. Biol. 68: $515-524$.

Loeb M.J., Kochansky J., Wagner R.M. \& Woods C.W. 1998: Structure-function analysis of Lymantria testis ecdysiotropin: a search for the active core. - Arch. Insect Biochem. Physiol. 38: $11-18$.

Loeb M.J., De Loof A., Gelman D.B., Hakim R.S., Jaffe H., Kochansky J.P., Meola S.M., Schoofs L., Steel C., VafopouLOU X., Wagner R.M. \& Woods C.W. 2001: Testis ecdysiotropin, an insect gonadotropin that induces synthesis of ecdysteroid. - Arch. Insect Biochem. 47: 181-188.

Mancini K. \& Dolder H. 2004: Dichotomic spermiogenesis in Euptoieta hegesia (Lepidoptera: Nymphalidae). - Braz. J. Morphol. Sci. 21: 13-23.

Manogem E.M. \& NaIR V.S.K. 2013: Dynamics of dichotomous spermiogenesis of Spodoptera mauritia (Boisd.) Lepidoptera: Noctuidae. - J. Cell Tiss. Res. 13: 3465-3471.

Meola S.M., Loeb M., Kochansky J.P., Wagner R., Beetham P., Wright M.S., Mouneimne Y. \& Meola S.M. \& Loeb M.J. 1995: Unique intertesticular tissue complex in larvae of Heliothis virescens (F.) (Lepidoptera: Noctuidae). - Int. J. Insect Morphol. 24: 443-457.

MikolajczyK P. \& Cymborowski B. 1993: Lower temperature influences developmental rhythms of the wax moth Galleria mellonella: putative role of ecdysteroids. - Comp. Biochem. Phys. (A) 105: 57-66.

Mochida O. \& Yoshimeki M. 1962: Relations with development of the gonads, dimensional changes of the corpora allata, and duration of post-diapauseperiod in hibernating larvae of the rice stem borer. - Jpn. J. Appl. Entomol. Z. 6: 114-123.

Muszynska-Pytel M., Trzcinska R., Aubry M., Pszczolkowski M.A. \& Cymborowski B. 1993: Regulation of prothoracic gland activity in diapausing larvae of the wax moth, Galleria mellonella L. (Lepidoptera). — Insect Biochem. Mol. Biol. 23: $33-41$.

Nowock J. 1972: Induction of imaginal differentiation by ecdysone in testes of Ephestia kuhniella. - J. Insect Physiol. 8: 1699-1704.

Nowock J. 1973: Growth and metamorphosis in the testes of Ephestia kuhniella, in vitro. - J. Insect Physiol. 19: 941-949.

Pereira M.C. \& Santos D.C. 2015: Testis morphology and dichotomic spermatogenesis in the sugarcane borer Diatraea saccharalis (F.) (Lepidoptera: Crambidae). - Neotrop. Entomol. 44: 481-488.

PerveEn F. 2011: Effects of sublethal doses of chlorfluazuron on the testicular biochemical constituents of Spodoptera litura (Lepidoptera: Noctuidae). — Afr. J. Biotechnol. 10: 8956-8964.

Perveen F., Mehmood S.A. \& Yasmin S. 2011: Effects of sublethal doses of chlorfluazuron on pupal-testis in the common cutworm, Spodoptera litura (F.) (Lepidoptera: Noctuidae). J. Agric. Sci. Technol. (A) 1: 890-896.
Phillips D.M. 1970: Insect sperm: their structure and morphogenesis. - J. Cell Biol. 44: 243-277.

Polanska M.A., Ciuk M.A., Cymborowski B. \& Bebas P. 2005: Germ cell death in the testis and its relation to spermatogenesis in the wax moth, Galleria mellonella (Lepidoptera: Pyralidae), effects of facultative diapause. - J. Exp. Zool. (A) 303: 1013-1029.

Raikhel A.S., Brown M.R. \& Belles X. 2005: Hormonal control of reproductive processes. In Gilbert L.I., Reinecke L.H., Reinecke J.P. \& Adams T.S. 1983: Morphology of the male reproductive tract of mature larval, pupal, and adult tobacco hornworms (Lepidoptera: Sphingidae), Manduca sexta. Ann. Entomol. Soc. Am. 76: 365-375.

RETNAKARAN A. 1970: The male reproductive system of the spruce budworm, Choristoneura fumiferana (Lepidoptera: Tortricidae). I. Spermatogenesis. - Ann. Entomol. Soc. Am. 63: 851-859.

Riddiford L.M., Cherbas P. \& Truman J.W. 2001: Ecdysone receptors and their biological actions. - Vitam. Horm. 60: 1-73.

RidDiford L.M., Hiruma K., Zhou X. \& Nelson C.A. 2003: Insights into the molecular basis of the hormonal control of molting and metamorphosis from Manduca sexta and Drosophila melanogaster. —Insect Biochem. Mol. Biol. 33: 1327-1338.

Riemann J.G. \& Giebultowicz J.M. 1992: Sperm maturation in the vasa deferentia of the gypsy moth, Lymantria dispar L. (Lepidoptera: Lymantriidae). - Int. J. Insect Morphol. 21: 271-284.

Riemann J.G., Thorson B.J. \& RuUd R.L. 1974: Daily cycle of release of sperm from the testes of the Mediterranean flour moth. - J. Insect Physiol. 20: 195-207.

Rountree D.B. \& Bollenbacher W.E. 1986: The release of the prothoracicotropic hormone in the tobacco hornworm, Manduca sexta, is controlled intrinsically by juvenile hormone. - $J$. Exp. Biol. 120: 41-58.

SAKURAi S., OKuda M. \& OHTAKi T. 1989: Juvenile hormone inhibits ecdysone secretion and responsiveness to prothoracicotropic hormone in prothoracic glands of Bombyx mori. - Gen. Comp. Endocr. 75: 222-230.

Sehnal F. 1966: Kritisches Studium der Bionomie und Biometric der in Verschiedenen Lebensbedingungen Gezuchteten Waschmotte Galleria mellonella (Lepidoptera). - Z. Wiss. Zool. Abt. (A) 174: 53-82.

SEth R.K., RaO D.K. \& Reynolds S.E. 2002: Movement of spermatozoa in the reproductive tract of adult male Spodoptera litura: Daily rhythm of sperm descent and the effect of light regime on male reproduction. - J. Insect Physiol. 48: 119-131.

Shimoda M., Kubo-Irie M., Ohta K., Irie M. \& Mohri H. 2007: Spermatogenesis in the testes of diapause and non-diapause pupae of the sweet potato hornworm, Agrius convolvuli (L.) (Lepidoptera: Sphingidae). — Zool. Sci. 24: 1036-1044.

Slama K. 2015: A new look at the nature of insect juvenile hormone with particular reference to studies carried out in the Czech Republic. - Eur. J. Entomol. 112: 567-590.

Smietanko A., Wisniewski J.R. \& Cymborowski B. 1989: Effect of low rearing temperature on development of Galleria mellonella larvae and their sensitivity to juvenilizing treatment. Comp. Biochem. Physiol. (A) 92: 163-169.

Sonoli S.B. \& Hooli M.A. 1992: Histological and histochemical studies of the apical cells of the cotton bollworm, Heliothis armigera (Hübner) (Lepidoptera: Noctuidae). - Int. J. Insect Morphol. 21: 263-270.

Sridevi R., Dutta-Gupta A. \& Ramamurty P.S. 1989: Spermatogenesis in Spodoptera litura (Lepidoptera: Noctuidae). - Entomon 14: 1-9. 
Su X.H., Chen J.L., Zhang X.J., Xue W., Liu H. \& Xing L.X. 2015: Testicular development and modes of apoptosis during spermatogenesis in various castes of the termite Reticulitermes labralis (Isoptera: Rhinotermitidae). - Arthr. Struct. Dev. 44: 630-638.

Sullivan A.A. \& Thummel C.S. 2003: Temporal profiles of nuclear receptor gene expression reveal coordinate transcriptional responses during Drosophila development. - Mol. Endocrinol. 17: 2125-2137.

TAKAKI K. \& SAKURAI S. 2003: Regulation of prothoracic gland ecdysteroidogenic activity leading to pupal metamorphosis. Insect Biochem. Mol. Biol. 33: 1189-1199.

TAKEUCHI S. 1969: Endocrinological studies on spermatogenesis in the silkworm, Bombyx mori. - Dev. Growth Differ. 11: $8-28$.

Tschudi-Rein K. \& Benz G. 1990: The bipotentiality of lepidopteran primary spermatocytes questioned. - Mitt. Schweiz. Entomol. Ges. 63: 81-85.
WigGLESWORTH V.B. 1936: The function of the corpus allatum in the growth and reproduction of Rhodnius prolixus (Hemiptera). - Q. J. Microsc. Sci. 79: 91-122.

Witalis J. \& Godula J. 1993: Postembryonal development of the testes in cotton leaf worm, Spodoptera littoralis (Boisd.) (Noctuidae, Lepidoptera). — Acta Biol. Hung. 44: 281-295.

Wyatt G.R. \& Davey K.G. 1996: Cellular and molecular actions of juvenile hormone. 2. Roles of juvenile hormone in adult insects. - Adv. Insect Physiol. 26: 1-155.

Zahera A. \& Tembhare D.B. 2016: Studies on developmental stages of spermatogenesis and effect of JH III and $\beta$-ecdysone on spermatogenesis in the aquatic beetle, Cybister tripunctatus (OL) (Coleoptera: Dytiscidae). — Bioscan 11: 897-901.

Received September 28, 2017; revised and accepted June 8, 2018 Published online August 17, 2018 